\title{
Hybrid modelling of MTO/ETO manufacturing environments for performance assessment
}

\section{Cátia Barbosa \& Américo Azevedo}

To cite this article: Cátia Barbosa \& Américo Azevedo (2018): Hybrid modelling of MTO/ETO manufacturing environments for performance assessment, International Journal of Production Research, DOI: 10.1080/00207543.2017.1421788

To link to this article: https://doi.org/10.1080/00207543.2017.1421788

$$
\text { 曲 Published online: } 11 \text { Jan } 2018 .
$$

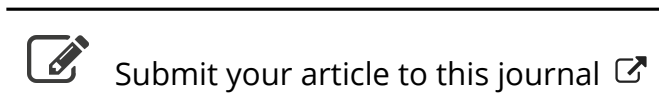

\section{LIIl Article views: 34}

\section{Q View related articles $\longleftarrow$}

View Crossmark data ¿ 


\title{
Hybrid modelling of MTO/ETO manufacturing environments for performance assessment
}

\author{
Cátia Barbosa ${ }^{\mathrm{a}, \mathrm{b}}$ and Américo Azevedo ${ }^{\mathrm{a}, \mathrm{b} *}$ \\ ${ }^{a}$ Faculty of Engineering, University of Porto, Porto, Portugal; ${ }^{b}$ Inesc TEC, Campus da FEUP, Porto, Portugal
}

(Received 6 June 2017; accepted 13 December 2017)

\begin{abstract}
Performance assessment is critical in today's competitive environments, where companies need to establish trade-offs between key competitive dimensions. The complexity of these environments calls for new approaches to performance assessment. Thus, in this work, we propose a novel conceptual framework for performance assessment in manufacturing environments combining different production strategies. Focus is laid on MTO/ETO combined environments and a threestage problem analysis is considered. Firstly, a hybrid SD-DES-ABS model approach addresses the needs of a system that handles different types of orders, processes and workforce allocation requirements; secondly, the model results for different demand scenarios are assessed using a one-way ANOVA analysis followed by a Tukey - Kramer's test, with pairwise comparisons for assessment of significant performance variations under different system operating policies. A full factorial Design of Experiments (DOE) analysis follows, for determining the relevant process parameters influencing the system performance. As an example of application of the proposed framework, we consider the case of an advanced manufacturing company, whose manufacturing environment encompasses combined MTO/ETO production strategies.
\end{abstract}

Keywords: ANOVA; design of experiments; engineer-to-order; hybrid simulation; make-to-order

\section{Introduction}

Modern manufacturing organisations are subject to high business pressures, including globalisation, market competition (Nudurupati et al. 2011), customer demand for customised, sophisticated, high-quality and innovative products (Chen 2008), shorter product's life cycles and increasingly complex production processes. These organisations must properly implement and manage operations strategies and improvement actions to remain competitive and satisfy customers efficiently and effectively. Hence, performance assessment is critical for challenging strategic choices and reviewing objectives as market circumstances change (Neely, Gregory, and Platts 1995).

Good performance of manufacturing organisations depends on dimensions as cost, response time, efficiency, service levels and quality of products and services. Establishing trade-offs among these entails competing in different positions of the spectrum between make-to-stock (MTS) and engineer-to-order (ETO) strategies, often resulting in combined strategies. The customer order decoupling point (CODP) reserves different products for customers with different requirements (Akinc and Meredith 2015). There is usually a dominant CODP (van Donk and van Doorne 2016) and its positioning reflects the company's strategic choice: make-to-stock (MTS), assemble-to-order (ATO), MTO and ETO (Rudberg and Wikner 2004).

In MTS, product specifications are set long before the customer makes the decision of ordering the products. Products are simple, with focus on productivity, operations and costs. Although companies operate under uncertainty, using demand forecasts and with risk of product obsolescence, the MTS strategy is appealing due to the high capacity utilisation and short lead times (Rafiei and Rabbani 2011). For companies following an ATO strategy, pre-manufactured components are assembled to the customers' specifications, when the customer order arrives. A MTO strategy includes configuring the products following a set of pre-defined attributes, and production according to a selected configuration; the customer chooses the product according to limited available options (Willner et al. 2014). MTO companies respond to deterministic demand, but are more vulnerable to disturbances, as disruptions in material supplies and demand variation. These operate with longer lead times and large order backlogs (Rafiei and Rabbani 2011). ETO manufacturers provide unique and complex products. These manufacturers must be flexible, providing products to the specific customers' needs and manufacturing in small quantities (Rudberg and Wikner 2004). Manufacturing the product is part of the manufacturing project and large cost penalties are imposed by customers for lateness.

\footnotetext{
*Corresponding author. Email: ala@fe.up.pt 
For a manufacturing organisation, the CODP may vary between products offered, or over time, resulting in combined production strategies. Manufacturing environments combining different production and operations strategies are very complex, involving several processes and resources and a variety of problems that may arise. This calls for using different methods to analyse different problems in the same production environment. The hybrid MTS/MTO combined strategies is one of the most dominant production strategies, drawing attention of academics and practitioners (Rafiei, Rabbani, and Alimardani 2013). On the contrary, as Hendry (2010) identified, MTO/ETO has received little attention in the literature. Only recently, due to the pressure that manufacturing companies have had to offer more customised products, and in search for more agility and flexibility (Grabenstetter and Usher 2014), attention has focused on MTO (Stevenson, Hendry, and Kingsman 2005) and ETO (Grabenstetter and Usher 2014) strategies. As engineering and production activities are core in MTO and ETO, an integrated approach, considering the influence of both activities in performance is needed. Hence, in this work, we focus on combined MTO/ETO operations environment.

Simulation modelling often arises as an alternative to quantitative models approaches for analysing complex manufacturing systems, particularly when time dynamics is important (Borshchev and Filippov 2004). It allows modelling systems, aiding in decision-making and performance assessment (Umeda and Zhang 2008). Hybrid simulation approaches result from the increased complexity of manufacturing systems, which require different methods for analysing different problems. These approaches combine at least two of three simulation methods - System Dynamics (SD), Discrete Event Simulation (DES) and Agent-Based Simulation (ABS) (Swinerd and McNaught 2012).

Considering the complexity of manufacturing systems combining different production strategies, and the capabilities of hybrid simulation in capturing the interactions among processes of different nature, we propose a novel conceptual framework for modelling and assessing performance of manufacturing environments where different production strategies co-exist. The framework focuses on MTO/ETO combined environments and considers a three-stage problem analysis. Firstly, a hybrid SD-DES-ABS approach addresses the needs of a system that handles different types of orders, processes and workforce allocation requirements; secondly, the model results for different demand scenarios are assessed using a one-way ANOVA analysis followed by a Tukey - Kramer's test, with pairwise comparisons for assessment of significant performance variations under different system operating policies. A full factorial Design of Experiments (DOE) analysis follows, for determining the relevant process parameters influencing the system performance. The proposed framework was applied to the case of an advanced manufacturing company, operating in a combined MTO/ETO strategy.

The remaining of the paper is organised as follows. Section 2 provides a literature overview of the topics relevant in the context of this work. Section 3 delves on the proposed modelling architecture, capturing the different modules in the system, and the model assumptions. Section 4 explores the case study company, and a justification for the company's selection for the application of the developed model; Section 5 explores the results from applying the modelling framework to the case study company. The paper finishes in Section 6, with the conclusions and future research directions.

\section{Theoretical background}

In this section, features and implications of MTO/ETO production environments, focusing on the challenges in managing and monitoring these systems are explored. Then, works using simulation approaches, applied to MTO/ETO are revised and we delve on the role that hybrid simulation approaches may have in representing different processes in MTO/ETO production strategies. Finally, the capabilities, strengths and weaknesses of the three simulation methods $\mathrm{SD}$, DES and ABS, are explored.

\section{Implications on MTO/ETO combined production strategies}

Even though MTO/ETO literature has received little attention, it is an important sector, with many small and medium enterprises operating under these strategies in different supply chains (Hendry 2010). These environments are characterised by different levels of customisation, long flow times, variable demand, product specifications, lead times and process duration (Hicks and Braiden 2000).

MTO and ETO strategies differ in some respects. In MTO, the design of the product exists at the time of order entry, although some modifications may be considered (Hendry 2010), for a set of pre-defined parameters and attributes (Willner et al. 2014); only manufacturing and assembling the product occur after the order has been confirmed. In ETO, designing, manufacturing and assembling the products occur when the order has been confirmed (Hendry 2010), with the order lead time including the manufacturing, engineering design and material acquisition. In ETO, product specifications are uncertain, with customers requiring the design of a completely new product (Akinc and Meredith 2015). The engineering process is simultaneously a bottleneck and a core process that is never outsourced (Grabenstetter and Usher 
2015). Variability and uncertainty are critical in ETO environments, due the different projects simultaneously carried, with different completion levels and constantly subject to changes (Adrodegari et al. 2015). The final products have complex structures that create many levels of assembly (Hicks and Braiden 2000), interfering in the production flow and coordination.

Most manufacturers do not exclusively manufacture under an ETO strategy, often earning most revenues from MTO products (Willner et al. 2014). In MTO and/or ETO environments, each product is tailored to the customers' needs. This translates into activities of design, production and delivery which are one of a kind, and can be modelled as the execution of a project. Low volume production is across MTO and ETO strategies. Different projects are simultaneously executed, competing for and sharing the same resources (Alfieri, Tolio, and Urgo 2012). Companies operating under these strategies are commonly organised as jobbing processes to achieve flexibility (Hendry 2010). Tardiness is an important measure of performance in MTO/ETO, because penalty costs depend on lateness, and early deliveries to customers may be an inconvenience. Other important measures of performance include resources' utilisation and inventory levels (Hicks and Braiden 2000).

\section{Simulation in combined production strategies}

Different previous studies are concerned with simulation in combined production strategies. Wang et al. (2011) developed a simulation model for studying operational decisions in combined MTS/MTO production. The authors evaluated the effect of two operational decisions in the system performance, namely semi-finished modules inventory policy, and the order admission control. Findings showed that the reorder point and the maximum work-in-progress (WIP) level had interlinked impacts on throughput and lead time. An extension of the model was proposed in Wang et al. (2012), with the authors relaxing some of the assumptions made in the earlier version of the study. The authors quantified the impact on the system cost of the MTS production lead time and its variation, and concluded that the MTS production lead time affected the system in the selection of the inventory policy and that a reduction in the MTS lead time could significantly reduce the total system cost. Also considering a combined MTS/MTO manufacturing system, Rocha et al. (2015) analysed the impact of two different mechanisms for releasing orders in the MTS and MTO stages. Results showed that reducing the percentage of tardy jobs could be achieved through a moderate increase in the level of stock of semi-finished products.

In Wu, Jiang, and Chang (2008), the authors explored the MTS/MTO strategy, in a semiconductor foundry. A scheduling method was proposed to achieve high levels of on-time delivery for MTO products and a high throughput for MTS products. Using DES, the authors assessed the performance of the proposed scheduling method and compared the results with other approaches in the literature. Beemsterboer et al. (2017) focused on four different methods for integrating MTS items in the control of a job-shop - MTO environment. The different methods were evaluated using DES in Python. A real factory working with mixed MTO, MTS and ATO strategies was considered in the study by Horng (2013). The author developed a simulation model for the combined manufacturing system, to assess different safety stock policies and performance.

Hicks and Braiden (2000) developed a simulation model based on the discrete event method, representing a MTO/ ETO manufacturing facility operating under the control of a computer-aided management system. The model represented the manufacture of different product families, using jobbing, batch, flow and assembly processes. The authors collected several manufacturing performance measures and found that the performance of the different dispatching rules was different at the components and end items levels. At the component level, and for a job shop, the shortest operation time first rule led to the best results, while at the product level, the least slack first and the earliest due date first rules performed best. In a different approach, Zschorn, Müller, and Ivanov (2016) studied a manufacturing company focusing on hybrid MTO/ETO production at the tactical level capacity management. The authors used a linear programming approach for determining production capacity, considering a single work station case. Afterwards, the preliminary idea of an agent-based simulation for a multiple-line case analysis was presented.

The use of simulation in combined production strategies has mostly been focusing on MTS/MTO strategies, with fewer studies addressing the needs of combined MTO/ETO. The analysed literature does not focus on the activities of product development in ETO strategies, nor in the customisation process in MTO strategies. Previous studies focused on production, for determining appropriate production scheduling and reorder points. We bridge this gap by establishing a conceptual model framework focusing on jointly analysing the development/customisation and production tasks. This framework is useful for predicting the performance of the system under different demand patterns and operating policies. $\mathrm{SD}$, DES and ABS methods are used for modelling and simulation of a MTO/ETO environment, and assessing performance in terms of tardiness, work-in-progress (WIP) and human resources utilisation. 


\section{Potential of hybrid simulation approaches}

Simulation allows studying the dynamic features of systems (Hicks and Braiden 2000), and is one of the most commonly used techniques in Operational Research (OR) (Swinerd and McNaught 2012). It is useful for modelling complex manufacturing systems, with applications including optimising designs and operations and assessing performance prior to implementation. Current demands from optimisation, incorporation of human decision-making, and high complexity of modern systems, push researchers for combining different simulation methods and achieving better understanding of complex interactions between processes of different nature (Swinerd and McNaught 2012). Developing a simulation model for a complex system using a single simulation method can be time-consuming, and often the use of the methods may become inappropriate under certain circumstances. Considering the different nature of processes involved in MTO/ ETO environments, a hybrid simulation approach becomes a valid alternative to study these systems.

Hybrid simulation approaches are becoming more relevant and frequent. However, combining two or more methods only is justified when the models from different methods are of equal importance for the overall goal of the simulation. This is due to the effort and precision required for combining models from different methods, and establishing information sharing. When the use of hybrid simulation is justified, many benefits are achieved. These include flexibility (Wang, Brême, and Moon 2014) and extraction of the best features of each simulation method, and the possibility of overcoming many challenges imposed by the complexity of modern systems (Swinerd and McNaught 2012). The purpose of hybrid simulation is solving complex real-world problems, using different methods to tackle different aspects of a given situation (Morgan, Howick, and Belton 2016), by complementarity of the strengths in each individual simulation method (Wang, Brême, and Moon 2014).

Examples of the use of hybrid simulation approaches include supply chain management (Umeda and Zhang 2008), enterprise simulation (Rabelo et al. 2005), hierarchical production planning (Venkateswaran and Son 2005), software project planning and management (Rus, Collofello, and Lakey 1999), material handling systems (Hao and Shen 2008) and life cycle assessment (Wang, Brême, and Moon 2014).

\section{Simulation methods}

Appropriate simulation model building starts with the adequate choice of method(s) for model development. Different simulation methods have different strengths and weaknesses, and understanding these is key for proper model development. The structure of the system and the objectives of the simulation should influence the choice of methods.

SD, initially called Industrial Dynamics, was proposed by Jay W. Forrester at the MIT, in the 1950s (Borshchev and Filippov 2004). It focuses on an aggregated view of the systems, and feedback mechanisms, with system changes associated to changes in the system structure. Its basic structures include sources, stocks, flows, sinks, feedback loops and variables. Finite differential equations capture interactions among sub-systems and feedback loops are responsible for dynamic complexity (Lättilä, Hilletofth, and Lin 2010). Its common applications include strategic planning, supply chain, workforce management, software development, markets and competition, manpower and personnel and project management (Borshchev and Filippov 2004; Lättilä, Hilletofth, and Lin 2010). It is a continuous simulation method, in which neither mapping discrete events is possible, nor considering detailed information.

Unlike SD, DES, whose origins date back to the 1960s, requires using accurate data about the system's operation. Its most important elements include entities, activities, resources, queues and events, with entities acting as passive elements flowing through blocks of activities, queues, suffering delays, seizing and releasing resources (Borshchev and Filippov 2004). The model state variables change in discrete points in time - events. DES has commonly ben applied to manufacturing settings, for evaluating alternative routing, planning and scheduling (Rabelo et al. 2005), warehouse operations, pedestrian movement, and traffic models. High data demands are one of the flaws of DES.

ABS adopts a microscopic approach, with agents exhibiting behaviour at the individual level; the macro-level behaviour results from the individual agents' interactions (Wang, Zheng, and Zhao 2013). Agents in an environment communicate with each other according to pre-defined rules and may present properties as proactiveness, reactiveness, responsiveness, social and leaning ability, learning and spatial awareness; may be representative of entities in a system, as human beings, animals or institutions rules (Borshchev and Filippov 2004). ABS has been used in applications in businesses, including manufacturing, supply chain management, maintenance (Lättilä, Hilletofth, and Lin 2010) and individual behaviour rules (Borshchev and Filippov 2004). As many details as possible are used for representing the characteristics of the elements in the system, and there is a high data demand, which may be challenging.

Borshchev and Filippov (2004) reported several application areas for the simulation methods. Considering the applications reported and the scope of this work, we are interested in the applications of manpower and personnel, project management, and factory floor. Manpower and personnel is important due to the many human resources in MTO/ETO 
environments, both in production and project development. It is usually modelled using SD and ABS, whereas SD focuses on workforce management issues (Aburawi and Hafeez 2009), and ABS on the individual agents' behaviour (Borshchev and Filippov 2004). The new product development in ETO can be modelled as a project, which justifies the need to consider project management in the model, commonly simulated using SD. Finally, shop floor operations are modelled using DES, which is the simulation method we adopted for the production stage.

Considering the above, we propose using a novel hybrid simulation approach (Barbosa and Azevedo 2015) to analyse the complex MTO/ETO manufacturing environment.

\section{Conceptual framework}

Conceptual modelling corresponds to abstracting a model from a real system. Considering the objectives of the simulation, the modelling stage is important for defining the key features of the system, the methods to use in developing the simulation model, the data requirements, the validity of the model and the level of confidence given to the model results (Robinson 2008).

Our research objective is developing a model for performance assessment of a MTO/ETO combined manufacturing environment operating under different policies, considering the relevant competitive dimensions and main system features. In the first stage of problem analysis, the hybrid simulation model is constructed, considering the specific features of combined MTO/ETO environments. Building on the identified applications for the different simulation methods, the system structure and most suitable simulation methods for analysing each part of the MTO/ETO environment are discussed and assessed.

To assess the model results for the system operating under different policies, and understanding the differences in the performance measures, appropriate statistical techniques are required. Selected statistical techniques must allow comparing alternative scenarios and searching for a solution to the problem being analysed (Robinson 2004). A one-way analysis of variance (ANOVA), followed by a Tukey-Kramer's post hoc comparison allows assessing the statistically significant differences in performance for the different operating policies. Finally, factorial design from DOE methodology (Antony 2014) is used for generating and assessing the effect of different system parameters in the relevant performance measures.

\section{Hybrid simulation model}

Conceptual model building started with identifying the relevant system features, the simulation methods to use in the different system parts and the information sharing between modules from different methods. Figure 1 presents an overview of the use of the simulation methods and the target system parts. SD was used at a higher abstraction level, modelling the project management tasks in ETO and the customisation tasks in MTO. Each new project for developing products under the ETO strategy was considered an agent, with a built-in SD behaviour. The SD method was also used

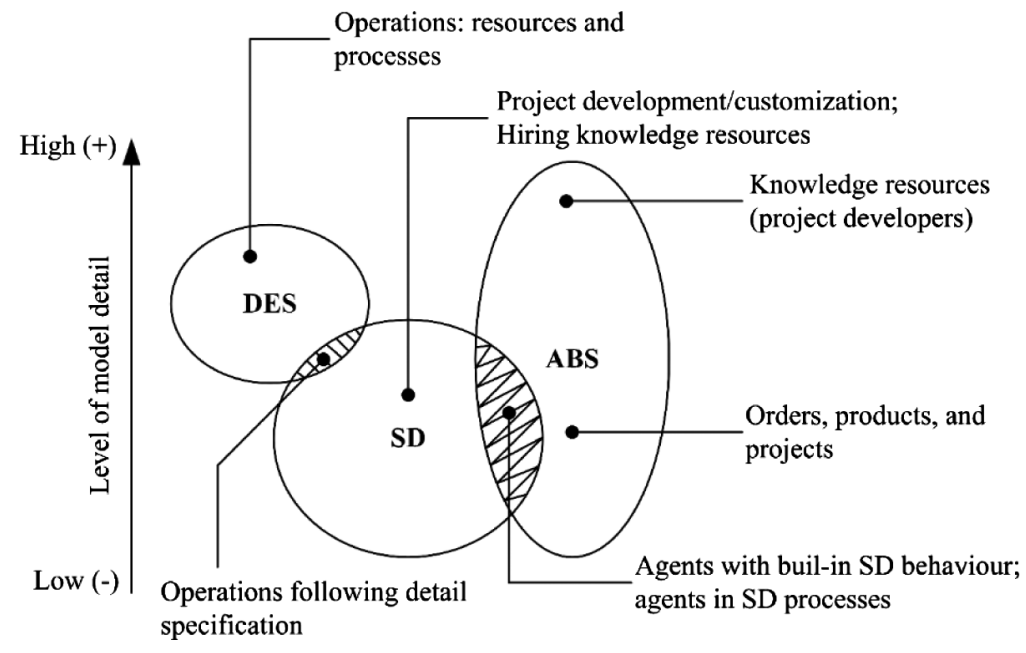

Figure 1. Modelling hybrid simulation approach and MTO/ETO manufacturing system parts. 


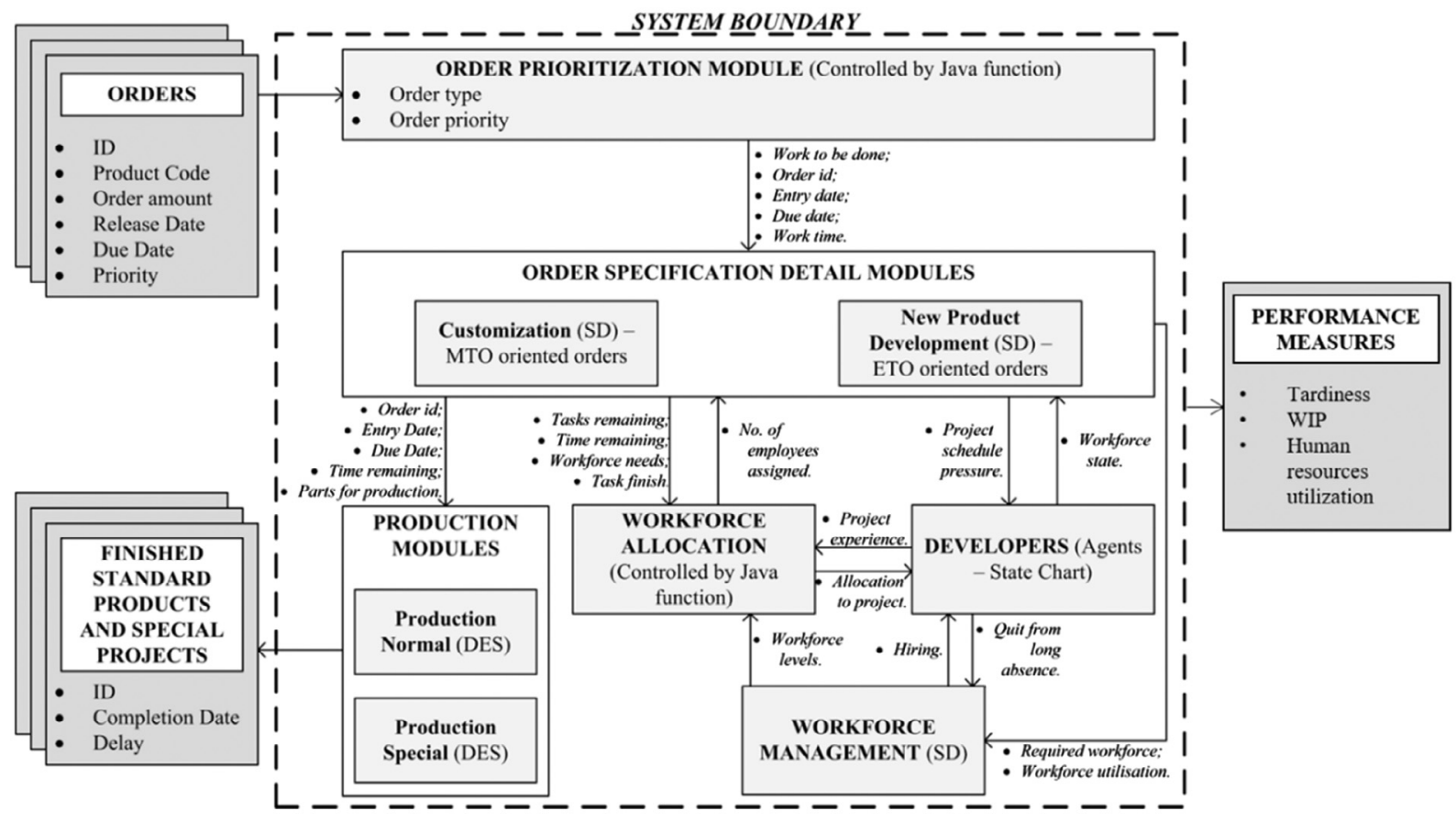

Figure 2. Detailed architecture of the hybrid integrated SD-DES-ABS model for performance assessment in manufacturing environments with combined MTO/ETO production strategies.

for modelling the function of hiring staff for the development of projects, considering the projects' needs. Each project developer, henceforth called developer, was modelled as an agent, whose internal state influenced the number of developers available for project development and customisation. The SD model of hiring developers influenced the number of active developers and the developers' internal state influenced the allocation to the project development. When the development of a project or customisation tasks finished, production started. The shop floor operations were modelled and simulated using DES, with the shop floor employees and machine resources modelled as entities. In the proposed model, despite the model being built in a main agent, there is no direct interaction between DES and ABS models.

Figure 2 presents the detailed model architecture, built upon the specifications set in Figure 1. There are six modules in the system, namely, the order prioritisation, order specification detail - customisation, new product development workforce allocation, workforce management, production - production normal, production special - and developers. Each module is explained in detail in the following sections. Orders may be for standard products - MTO oriented orders - or may be for special projects - ETO-oriented orders.

Different model designs can be adopted in hybrid simulation approaches (Swinerd and McNaught 2012; Morgan, Howick, and Belton 2016; Barbosa and Azevedo 2017). The model runs in a generally integrated design, with simultaneous modules' execution and feedback mechanisms between the different modules. The order prioritisation model is executed once in the beginning of each week of simulation to assess the new orders. Then, the order specification detail modules follow, according to the type of order (ETO or MTO). The order specification modules for ETO- and MTO-oriented orders do not interact, but share common resources, the developers. The order specification detail and production modules occur sequentially, with production following customisation and new product development. The workforce allocation function is executed upon call, in discrete points in time, establishing bi-directional communication with the developers and order specification detail modules, as represented in Figure 2.

In the modelling framework, multiple orders for standard products and new product development projects are allowed. The model assumes prior approval of the orders input to the system. The deliveries of finished products/projects, are not in the scope of the model. Once an order is completed, it is removed from the system, with a record of its delay. 


\section{Order prioritisation}

In the beginning of each simulation week, new orders are input to the system, by the execution of an event called Demand. In the order prioritisation module, orders are sorted by the due date and a priority level. First, the system verifies the order type - standard products or special projects. When the order is for standard products, the system verifies the due date of the new order and compares it with the orders in the system. When the due date of the new order is before the due date of the orders in the system, the new order is given priority over the existing ones - earliest due date first (EDF). If the due date of the new order is later than the existing orders, the new order is placed in last position. In case of due date equality with the existing orders, the orders' priorities are compared. If the priority of the new order is higher, the new order is given priority, otherwise is placed as the least prior among those with equal due date.

When the new order is for an ETO product, henceforth called special project, the project due date is considered. A percentage of the total time available for the special project is allocated to the development stage, and the remaining is allocated to production. The special project is input to the system and the resources are allocated to it in the resource allocation module. The special project development starts immediately.

\section{Order specification detail}

After orders' sorting, these are allocated to customisation or special projects categories. The order specification detail modules correspond to the customisation (MTO) and special projects' development (ETO). ETO products own the features of a project: temporariness and uniqueness, hence, every product is the result of a project (Yang 2013).

Despite the relevance of traditional project management tools, as the programme evaluation and review technique (PERT) (Sterman 1992), which consider a sequential and functional approach during development (Rodrigues, Dharmaraj, and Shrinivasa Rao 2006), these do not address the dynamic complexity created by delays, interdependencies, and multiple activities that exist in large projects (Sterman 1992). SD models are good at capturing the dynamic behaviour of factors associated to projects and interactions among them. These have been widely and successfully used in managing development projects, where managing the project takes a holistic view of the system, focusing on feedback mechanisms, allowing understanding the connection amid project dynamics and performance (Rodrigues 1994). The project development is modelled considering an initial stock of work to be done and a final stock of finished work. The finished work flows from work to be done to finished work, considering the staff allocated to the project, but ignoring which work is done and by whom it is done. Disruptive factors in project execution may be considered, as rework, change in project scope, quality compliance and productivity (Rodrigues 1994).

To address the effects of dynamic changes during project development, we used SD for the project development and customisation. Different computer models using SD for project management have been reported in the literature. Huot and Sylvestre (1985) developed a SD model for the construction management of a major building. The model consisted of three subsystems, including design, construction and procurement progress. Sterman (1992) described the use of SD for the management of large scale projects, and discussed the appropriateness of the method as an analytical tool in the NPD process. Also, Rodrigues and Bowers (1996) discussed the role of SD approaches in project management. Lyneis and Ford (2007) described the core model structure groups used in SD models in NPD, including project features as a collection of tasks performed in sequence or in parallel, the rework cycle, that represents a major source of challenges, the project control, intended for modelling the efforts in closing a performance gap, and the ripple and knock-on effects, that represent the impact that project control efforts have on rework and productivity. Rodrigues, Dharmaraj, and Shrinivasa Rao (2006) developed a SD model to analyse the product development dynamics and assess the competence loss of project staff when project scope changes occur. This model is a refined version of the model by Balaji and James (2005), by considering the competence loss. The SD model by Reddi and Moon (2013) addresses the interactions between the NPD and the engineering change management processes at the supply chain level. Different supply chain actors interact with the original equipment manufacturer (OEM) in different stages of the NPD process. Despite the relevance of this model, it is designed to be applied at the supply chain level and considering multiple actors involved in the NPD process. Also, DES could be a useful method for modelling the NPD process, especially for considering engineering changes, however, this would result in complex and large amounts of data (Reddi and Moon 2013). Given the successful application of SD to NPD, and as we are considering a more firm-centric NPD process, we adopted the model by Rodrigues, Dharmaraj, and Shrinivasa Rao (2006) for developing and managing special projects.

To tackle constraints from material resources, missing in the original model by Rodrigues, Dharmaraj, and Shrinivasa Rao (2006), we added a stock of materials, Figure 3(a), affecting the project development. Each project is an agent, whose internal behaviour is represented in SD. Customisation tasks are a simplified representation, with an initial stock of orders for customisation, and orders flowing from customisation products to completed customisation depending on 


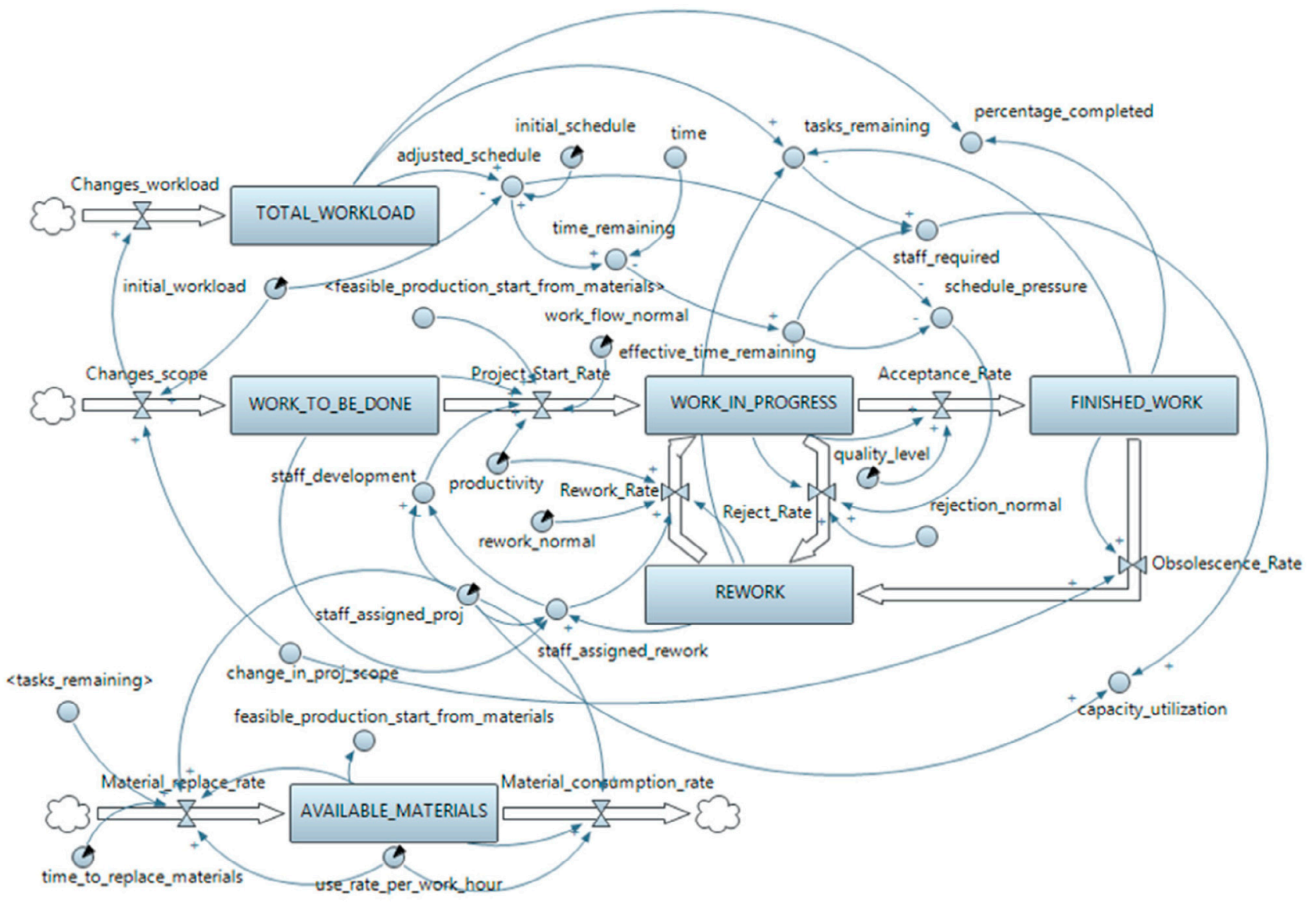

(A)

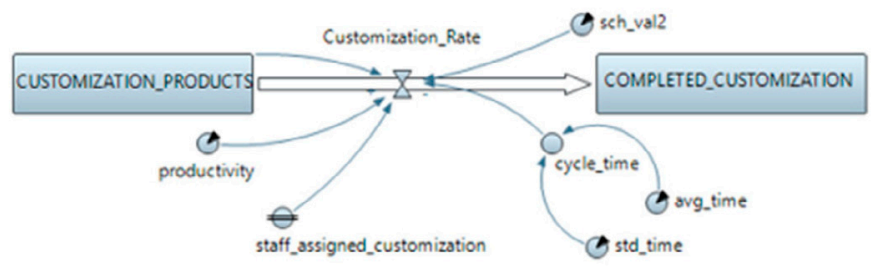

(B)

Figure 3. Implementation modules. (a) Special project development module and (b) Customisation tasks.

the staff allocated to customisation, as in Figure 3(b). Low variability in the cycle_time was considered for customisation, as these are routine tasks.

The order specification detail modules receive information from the order prioritisation module. For standard products, the customisation module receives the number of orders to be customised. To calculate the developers allocated to customisation, a time frame is established for completing these tasks. The special projects receive information about workload, the project due date and the project entry date. In the simulation, there is a schedule determining the working hours. An event, Schedule Eval, assesses the state of the schedule. When the schedule is off the parameter sch_val2 (Figure 3(b)) is set to zero by the event, and the rate of the tasks is set to zero; when the schedule is on, this parameter is set to one. The schedule value influences all activities in the system.

The workforce levels in each special project and customisation tasks are dynamic, and given by the parameters staff_assigned_proj and staff_assigned_customisation, in Figure 3. Whenever a developer is missing from work or 
providing support to other developers, its contribution to the project or customisation is not considered. The productivity in each project depends on the developers allocated to the project, and is given by Equation (1):

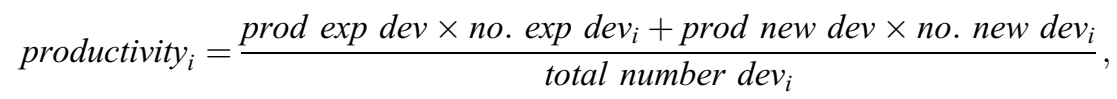

where productivity $_{i}$, no. exp $\operatorname{dev}_{i}$, no. new dev ${ }_{i}$, and total number $\operatorname{dev}_{i}$ are, respectively, the productivity factor, the number of experienced developers, the number of new developers, and the total number of developers in project $i$; prod exp dev and prod new dev correspond to the productivity factors associated to experienced and new developers.

During project development, there is a constant update of the required workforce and the workforce capacity utilisation. These are given by Equations (2) and (3), respectively:

$$
\begin{gathered}
\text { staff_required }_{i}=\left\{\begin{array}{c}
\text { tasks_remaining }_{i} / \text { effective_time_remaining } \\
\text { maximum admissible } \text { effective_time_remaining }_{i}>0,
\end{array},\right. \\
\text { capacity_utilisation }_{i}=\frac{\text { staff_required }_{i}}{\text { staff_assigned_proj }_{i}},
\end{gathered}
$$

where staff_required $_{i}$, tasks_remaining, effective_time_remaining ${ }_{i}$, and staff_assigned_proj $j_{i}$ correspond, respectively, to the developers required to accomplish the delivery date, the tasks which have yet to be fulfilled, the time remaining until the end of the project, excluding weekend and schedule off hours, and the number of staff allocated to project $i$ by the workforce allocation function. The required staff when the project exceeds the due date is set to a maximum admissible number of developers.

\section{Production}

Production of the standard products and the special projects starts after the order specification detail activities. DES, as referred in Section 2.4. is widely used at the operational level, allowing studying processes as sequences of activities, with entities flowing through those activities. It allows tracking the status of individual entities and resources in the shop floor, for estimating performance measures associated with those entities (Venkateswaran and Son 2005). For this, DES was selected for representing shop floor operations.

An event is triggered when customisation and/or special projects development finish, and production starts. The production module requires the type of product and the amount to be produced as input, and the parameters for the processing times stochastic distributions. Even though the orders are input for production according to their due date, different queueing rules (EDF, first-in-first-out (FIFO), priority based, and shortest processing time first (SPTF)) are used for the products flowing through the production system. When the number of components in an order is produced, the order is considered finished. For shop floor resources allocation, special projects are always given priority over the standard products.

\section{Workforce allocation}

In the literature referring to multi-project management, the resource allocation between simultaneous projects is a main topic (Engwall and Jerbrant 2003). For this, the workforce allocation function is relevant in the context of this work.

The workforce allocation function was developed in Java code. First, the proportion of staff to be allocated to each project is calculated, based on the workforce needs of each project - given by the parameter staff_required, Figure 3(a), from the special projects - and that the customisation tasks must be completed within an established time frame, as represented in Equations (4) and (5):

$$
\text { proportion } \text { staff }_{i}=\frac{\text { staff required }}{\sum_{i} \text { staff required }+ \text { staff requiredcustomization }},
$$




$$
\text { staff required customization }=\frac{\text { tasks in customization }}{\text { time frame }(\text { in hours })},
$$

where proportion staff $f_{i}$ is the proportion of staff to be allocated to project $i$, staff required customisation is the total staff that should be allocated to customisation, and tasks in customisation is the total number of standard products that must be customised.

Following, the proportion staff $i$ is multiplied by the number of developers available, to assess the number of developers to assign to each project. For the time zero of simulation, the developers are randomly assigned to the projects, respecting the calculated values of staff to be assigned to each project and to the customisation tasks. For the remaining re-evaluations of the workforce allocation function, the project developers are preferentially attributed to the project in which they spent most time. In case the preferred project already has all the developers assigned, the developer is assigned to another random project which not yet has all developers assigned.

The workforce allocation function is called upon the following situations: beginning of the simulation, beginning of every week, when executing the event Demand, for re-assessing the workforce needs of each project, and updating the developers' population when a new developer has been hired; when a developer quits from job; when customisation tasks end; and when a special project ends.

\section{Workforce management}

Workforce management refers to assessing the current workforce, determining future needs and finding the gap between these for establishing solutions that aid in accomplishing the organisational needs (Lianjun et al. 2007). It is key for ensuring the availability of adequate workforce in the appropriate time and place (Aburawi and Hafeez 2009). Workforce management deals with subjective yet quantifiable variables as workforce skills and ability. It includes activities as recruiting, selecting, classifying, training, performance management and retention (Lianjun et al. 2007).

SD is widely used in assessing the dynamics of human resource management. Considering the work in Lianjun et al. (2007), we developed a simplified SD workforce management model for the project developers, considering the hiring and selection processes and excluding the training, performance management and retention functions. The model has three stocks, Hiring in Process, Total Developers and Expected Utilisation. The Total Developers stock represents the current number of developers, Hiring in Process the number of people being considered for hiring, and Expected Utilisation the forecasted levels of the developers' utilisation, based on the values recorded in the order specification detail modules. Without projects in the system there is no hiring of developers. Hiring depends on the gap between the current number of developers and the difference between the required and the desired workforce, considering the projects' needs calculated in the order specification detail modules.

A maximum allowable workforce is imposed to the model, to avoid sudden hiring near the end of the projects or when projects are delayed. All candidates who are hired start as unexperienced developers. Progression to experienced developers is achieved in the project developers' module.

\section{Project developers}

In the overall system, each developer is an agent, with a defined internal state. The effort of developers may vary over time, considering their availability or joint execution of different activities (Alfieri, Tolio, and Urgo 2012); thereby we consider the developers state one of the most important drivers of project execution and success.

Each developer is an agent, whose initial state is defined as experienced or new employee. New and experienced developers may be absent or working; yet, while the working stare of new developers is simple, for experienced developers it is sub-divided as on job or training, as in Figure 4. The following assumptions are valid:

- Training function occurs when there are new developers;

- New developers are more likely to be absent than experienced developers;

- New developers become experienced according to a training rate;

- Developers can quit from job;

- The probability of a developer becoming absent increases when there are no special projects in the system or when the pressure in the project the agent is allocated to is higher than a given value;

- Developers statistics, as time active, time absent, time allocated to each project, time training may be retrieved and projects assigned to may be recorded by the action of an agent internal event called Time in Project. 


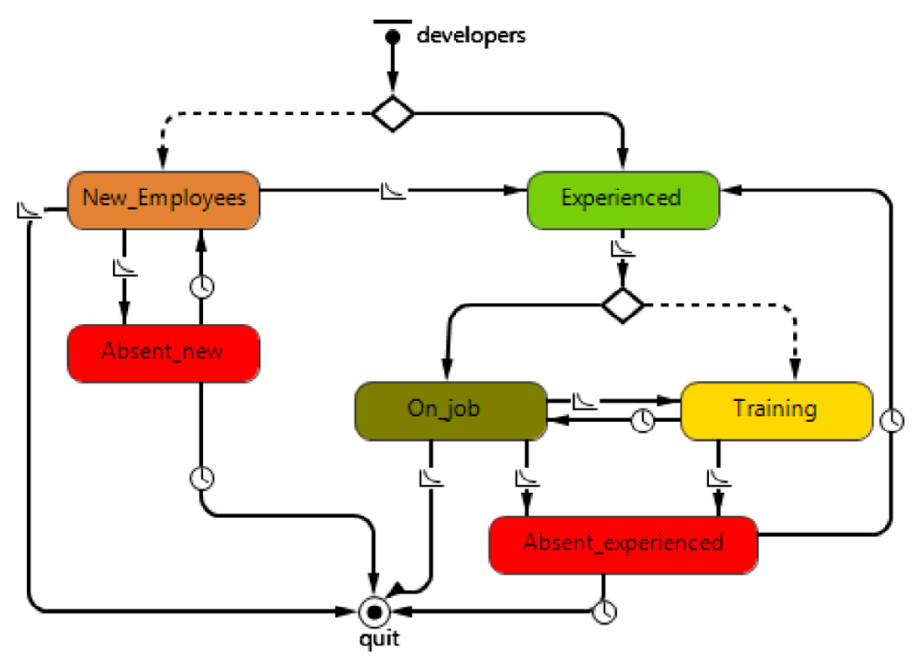

Figure 4. A state chart of the project developers.

\section{Model assumptions}

In the model implementation, the following assumptions were considered:

- The orders for standard products depart customisation by the order they were initially sorted in the order prioritisation;

- In production, neither set-up times, nor raw material shortage are considered. Infinite supply of raw materials and buffer sizes between the different work centres exist. Transport time between work centres is neglected. Production of standard products and special projects occur following different process logic, but share resources - machines and shop floor employees;

- Shop floor employees were modelled as entities;

- For the workforce allocation, all developers are considered, regardless their internal state. An absent developer may be allocated to a project. A developer stops being considered for allocation when quitting from job. This may have impact in the model outcomes, as when a single developer is assigned to a project and is absent, the project development stops. This effect is minimised by the weakly re-evaluation of the staff allocation to the projects;

- A limit to the number of developers to be hired is imposed;

- The realm of internal states considered for the developers is a simplified view of the many states that the workforce may assume.

\section{Communication between modules}

The proposed approach requires communication between models from different methods. The communication between these must occur timely, and with the appropriate information. Following, we describe the modules' communication.

\section{Order prioritisation - order specification detail}

The order prioritisation module has impact in the order specification detail modules; the opposite does not occur. The event Demand, inputs the orders in the combined MTO/ETO system. When it occurs, the week orders are sorted in the order prioritisation system and for each order, an agent is created. Each special project is an agent in the order specification detail; for standard products, new orders are placed in a stock of orders to be customised.

\section{Order specification detail - production}

An event, Add Production, is triggered when the stock of customised products increases one unit. This causes a standard order release to the shop floor and the event restart. For special projects, when the finished work equals the total project workload, the project development finishes and the project is input for production. 
Order specification detail - workforce allocation

When the workforce allocation function is called, the order specification detail modules transmit information to the workforce allocation function, concerning tasks remaining, required workforce, time remaining for the special project, and, when applicable, the project finish. In the opposite direction, the workforce allocation establishes the number and id of the developers to be allocated to the projects.

\section{Order specification detail - developers}

When a developer is assigned to a project and is absent or training new developers, this is reflected in the staff allocated to the projects. Every minute of simulation, the state of the developers and the number of real project developers contributing to the project are updated, through an event called Evaluate Staff State. An absent or training developer is assigned to a project, but is not contributing to the development in a certain period, affecting the productivity factor in the project.

Each project is associated to a schedule pressure. When the schedule pressure exceeds a certain value, it increases the rate of the developers becoming absent from work.

\section{Order specification detail - workforce management}

The order specification detail modules provide information to the workforce management module. The event Evaluate Staff State assesses the workforce required for each project and the workforce utilisation, and inputs the values to the workforce management.

\section{Workforce allocation - developers}

The workforce allocation function establishes the developers assigned to each project. A re-evaluation occurs when the workforce allocation function is called. Each developer has a record of the time spent in each project, information used by the workforce allocation function. Each developer will preferentially be assigned to the project he has spent more time in.

\section{Workforce allocation - workforce management}

The workforce allocation function must know the levels of project developers. When it is called, the level of staff in the workforce management module is input to it.

\section{Workforce management - developers}

Through the Demand event, the workforce levels in the workforce management module are verified. A new developer is created when hiring occurs. When a developer quits, the developers' stock is immediately reduced one unit.

\section{Assessment of significant differences among operating policies}

The second stage of the problem analysis encompasses assessing the significant differences among performance levels obtained for different system operating policies. This includes comparing alternative scenarios and developing a better understanding of the system. The analysis of variance (ANOVA) is a rigorous mean for assessing if changes in experimental factors have an effect in the system response and has been used along with simulation experiments (Robinson 2004) for comparing alternative scenarios. Given the objective of assessing differences in the system in response to alternative operating policies, a one-way ANOVA analysis followed by a post hoc Tukey-Kramer's test are considered appropriate for the analysis of the results.

Statistical analysis of variance (ANOVA) is often used along with simulation tools for interpreting data and assessing differences among the average performance of groups of items (Marzouk, ElMaraghy, and ElMaraghy 2016). The ANOVA test of hypothesis shows an overall difference between group means, and considers the comparison of two independent estimates of the variance of the population. The one-way ANOVA test does not allow inferring which groups of items differ, requiring post hoc comparison procedures for testing the differences among group means. Post hoc tests, as the Tukey-Kramer's, are used after the ANOVA test. The Tukey-Kramer's test can control type 1 errors (Ostertagová and Ostertag 2013), and was selected for the post hoc comparisons. 


\section{Assessment of relevant system parameters impact in performance}

The final stage of the problem analysis encompasses determining the system parameters, related to human resources and the project development, which influence the performance of the system. To conduct the analysis we used full factorial design methodology of DOE (Antony 2014) to create the simulation input parameters and assess the model results. Experimental design is primarily used for identifying important experimental factors that give most improvement in meeting the purposes of the simulation study (Robinson 2004).

Designed experiments are used for intentionally making changes to input system factors, and observing the changes in the process output. The information obtained can be used for improving the systems' performance. DOE encompasses planning, designing and analysing an experiment, so proper and valid conclusions may be retrieved.

Building on the previous discussion, Figure 5 shows the resulting proposed conceptual framework, including the hybrid simulation model development and the model application and results' analysis. An overview of the conceptual model steps is provided in the flow chart in Figure 6.

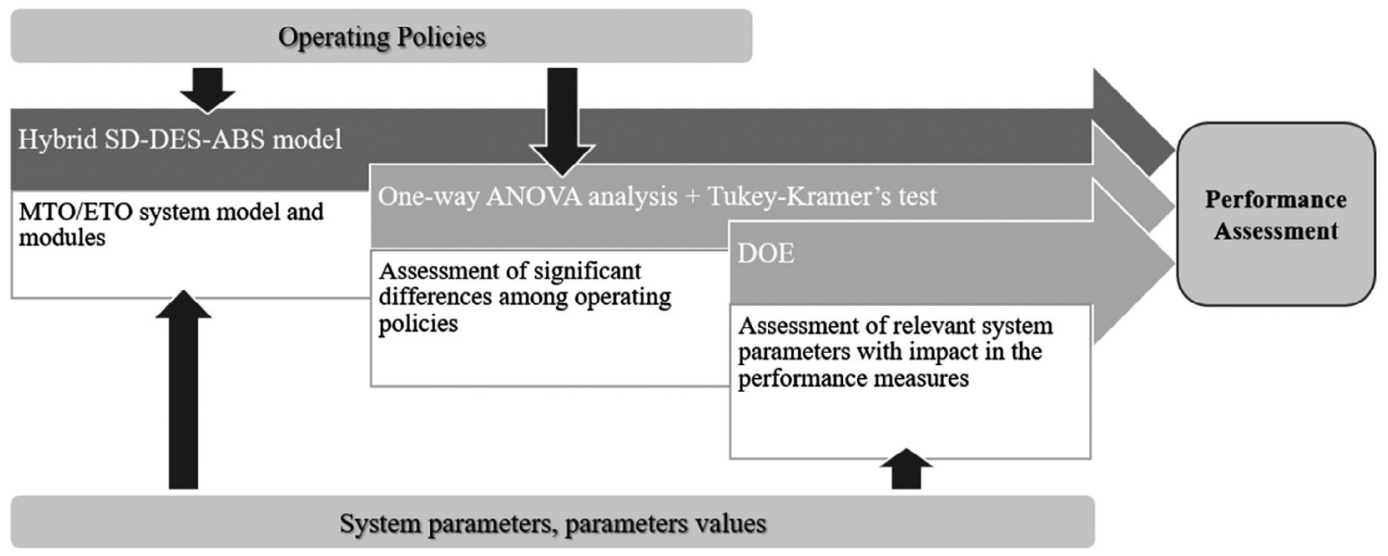

Figure 5. Proposed framework for the hybrid simulation model in MTO/ETO environments, with the model application and assessment of model output.

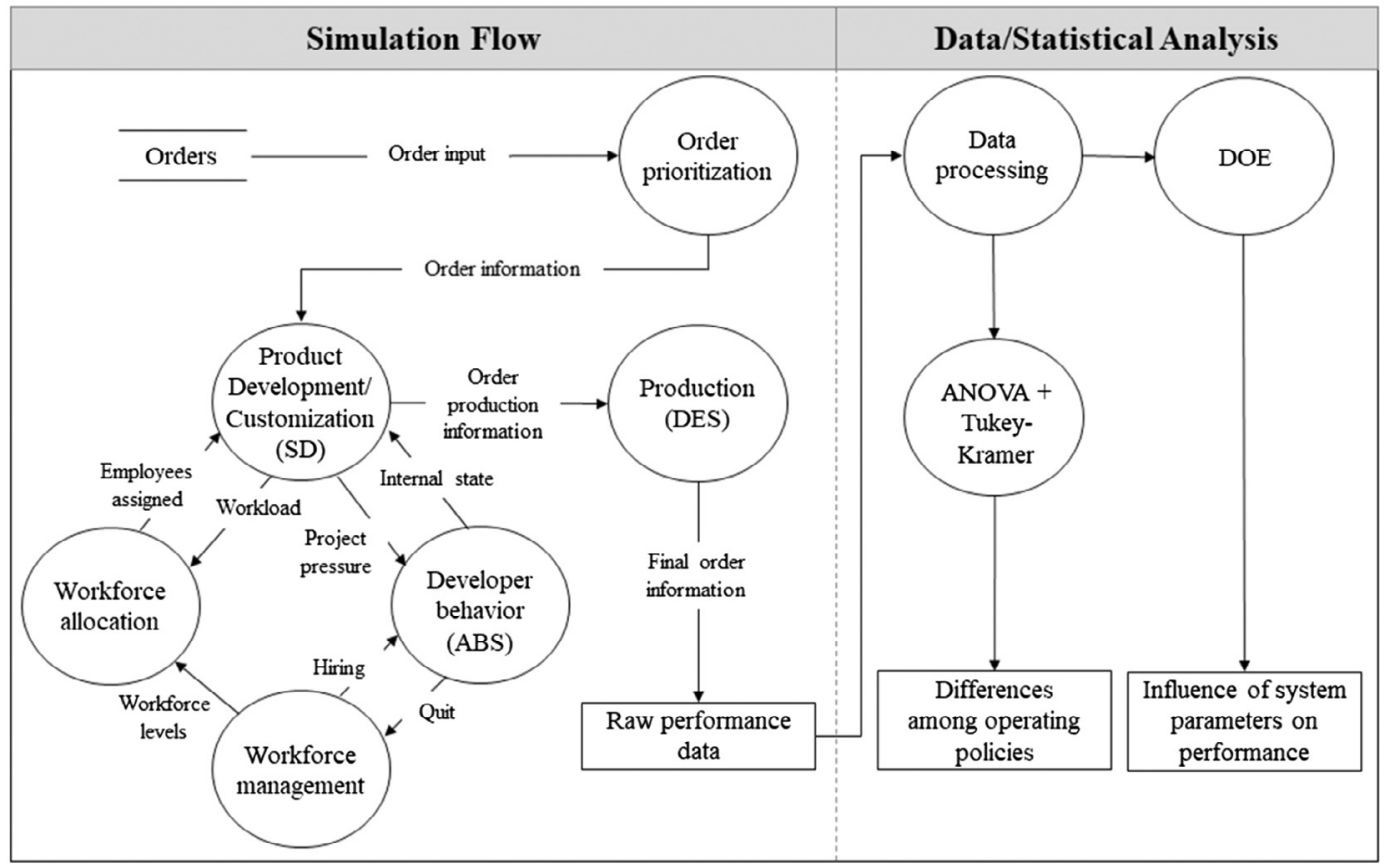

Figure 6. Conceptual model flow diagram. 


\section{Application case}

\section{The case study company}

To apply and test the proposed framework, the case of an advanced manufacturing company, producing customised high-technological conveyors, packaging and robotised palletisers solutions for the food and chemical industries, has been considered. The company operates in a combined MTO/ETO strategy, in a single facility, working in a process layout, with general-purpose equipment, low volume operations and high mix of products. Machines are grouped by function, and buffers guarantee material flows between machines. A total of six Work-Centres (WCs) make the production and assembly areas. Each WC has different number of machines - two in WC1, four in WC2, one in WC3, one in WC4, three in WC5 and two in WC6. The company produces standard products in a MTO strategy that prior to production are customised. Each standard product type follows a different route in the shop floor and has different processing times in each WC. Seven standard product families have been considered for the simulations, with the routes and processing times as in Table 3 from Appendix 1. Quality inspection occurs after each operation, in each WC, and requires in average two minutes. The facility works from Monday to Friday, from 7 am-12 pm to $1 \mathrm{pm}-7 \mathrm{pm}$.

The special projects are unique products that undergo an engineering process, including product specification, design, and selection of materials. Special projects' development encompasses interaction with the customer, and the product requirements are often changed. A specialised team develops the products to the customer's requirements and customises the products in the company portfolio. The special projects and the standard products, compete for resources at the production and development/customisation levels. Table 4 in Appendix 1 shows the average and standard deviation production times, in days, for the special projects in each WC. The values in Table 4 are estimates, as each special project is unique and processing times are highly variable. The special projects undergo processing in all WCs, but in WCs 3 and 4, where one machine is available, alternative machine resources are used. All processing times followed a normal distribution.

The selection of the case study company considered that this industrial setting is a good representative of the features of MTO/ETO combined environments. The case company operates with different levels of product customisation. As above referred, the company performs some parts customisation in standard products and develops new, fully customised products through special projects. Also, it operates with long flow times that can vary from a couple of weeks to a few months, under a highly variable demand pattern, with often uncertain product features, lead times and processes duration. It operates in a jobbing process, and internally develops activities of design, production and delivery.

\section{Implementation, validation and testing}

The model was implemented using the Anylogic platform. The choice of the software considered the multi-method modelling possibility, which enabled building the models combining SD, DES and ABS. Anylogic is a software based on Java that allows combining the three modelling methods in the development of a single model.

Model validation and verification are critical to ensure the model provides accurate information about the system under study. A model should be valid for the purposes it has been developed for. For verification purposes, the model was subject to intensive debugging by multiple runs and individual verification of each module's output, using different problem instances. As for validation purposes, and following some of the techniques proposed in (Sargent 2011), the model was subject to extreme condition tests, internal validity, operational graphics, and parameter variability.

\section{Results and analysis}

The model has been simulated to assess the effect of different demand data and process parameters on selected performance measures - tardiness at the product level, WIP, measured as the number of components in the system or the number of projects in production, human resources utilisation and late deliveries count. It considered the time units in hours and a fixed time step of $1 \times 10^{-5}$. The integration type was Euler and the model simulated six months of operations. The results presented are the average values from multiple simulation runs. In the first stage of problem analysis, the demand data was varied and the different operating policies considered were queuing policies:

- EDF - orders with lower due dates are given priority;

- FIFO - ordering per arrival;

- SPTF - orders with shortest processing times are given priority;

- Priority based - EDF (PB-EDF) - orders with lower due dates and higher priority are given priority; 
Secondly, considering a fixed demand pattern and operating policy, the impact of four process factors was considered at two levels - low and high.

\section{Variable demand data and queuing policies - one-way ANOVA analysis and Tukey-Kramer's test}

The first stage of the model output assessment considered different demand patterns and queuing policies. The demand patterns included no orders for special projects (No SP), $10 \%$ of orders for special projects $(10 \%$ SP), and $20 \%$ of orders are for special projects ( $20 \% \mathrm{SP})$. The parameters' values in Table 5 in Appendix 1 were kept constant throughout the experiments. Minitab was used for data analysis.

Figure 7 presents the average, standard deviation, maximum and minimum values for the different performance measures. The SPTF policy, Figure 7(a), achieves the highest average and maximum tardiness values for standard products, performing worst among the queuing policies. The EDF and PB-EDF policies achieved the lower tardiness values for standard products. Despite the increase in the tardiness of the special projects when the demand rises from 10 to $20 \%$, Figure 7(b), the recorded tardiness for the special projects is similar among the different queuing policies. The one-way ANOVA analysis, with $\alpha=0.05$, Table 1(a), shows significant differences in the tardiness of standard products for different queuing policies, but no significant differences in tardiness for the special projects in the same demand pattern, among different queuing policies. The Tukey-Kramer test, Table 1(b) shows that for different demand patterns, in the standard products, the EDF and PB-EDF, and the SPTF and the FIFO policies perform similarly.

The tardiness measures, for MTO products, at the product level, show that queuing policies considering the due date information of the product outperform policies based on the order of arrival and the processing time. This agrees with previous findings (Hicks and Braiden 2000; Lu, Huang, and Yang 2011) showing that, at the product level, EDF rules achieve better performance, while SPTF achieve worst performance levels. The absence of differences in performance for the different queueing policies for ETO products, may be explained by the fact that ETO projects were always given

(a)

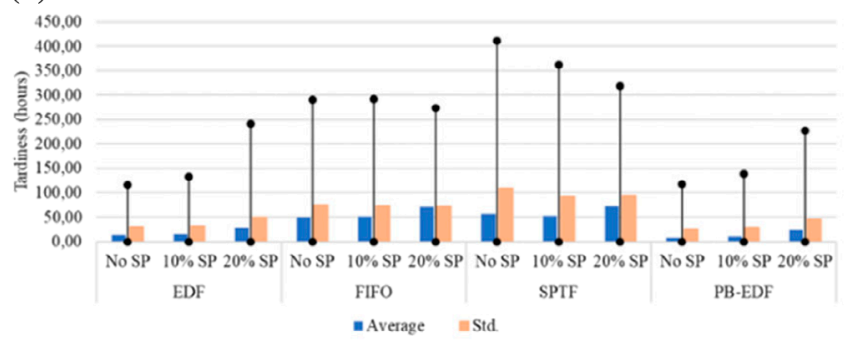

(c)

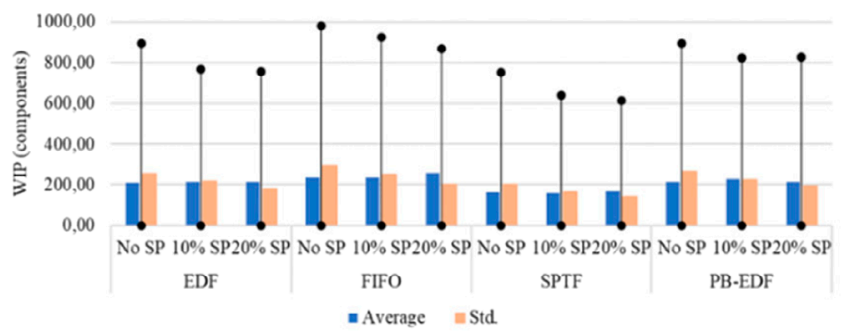

(e)

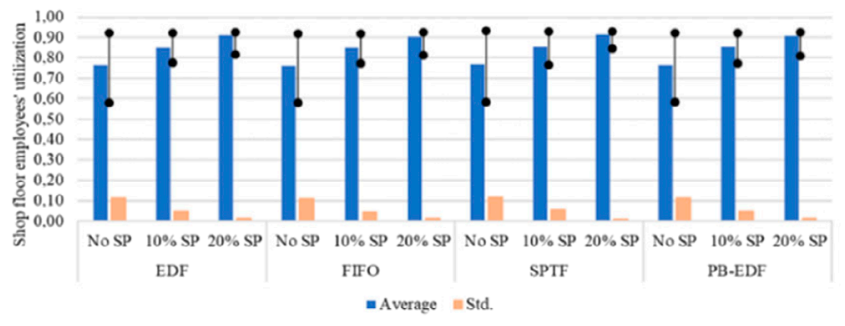

(b)

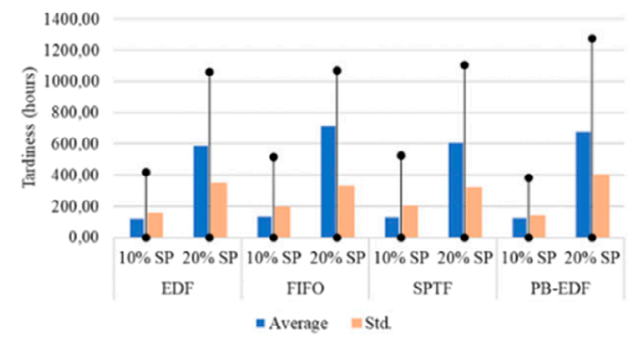

(d)

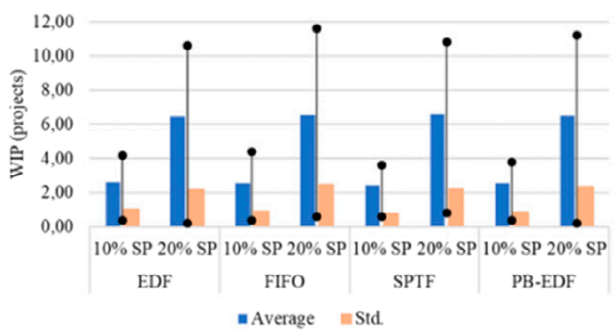

(f)

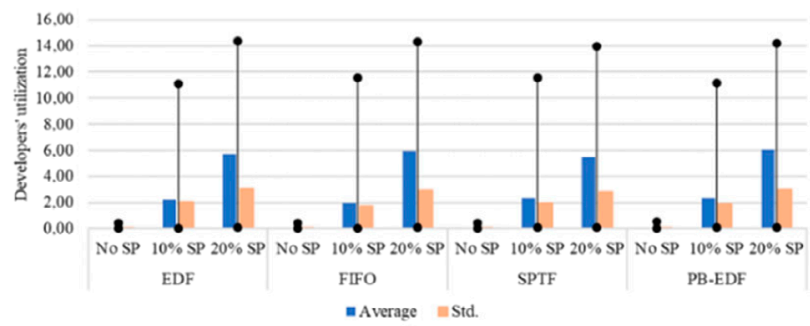

Figure 7. Average, standard deviation, maximum and minimum values for: (a) Tardiness standard products, (b)Tardiness special projects, (c) WIP standard products, (d) WIP special projects, (e) Shop floor employees' utilisation and (f) Developers' utilisation. 
Table 1. Comparison of the different queuing policies under different demand patterns for the different performance measures.

\begin{tabular}{|c|c|c|c|c|c|c|c|}
\hline & & & $\begin{array}{l}\text { Degrees of } \\
\text { freedom }\end{array}$ & Sum of squares & Mean square & $F$-value & $P$-value \\
\hline \multicolumn{8}{|c|}{ (a) One-way ANOVA } \\
\hline \multirow[t]{12}{*}{ No SP } & \multirow[t]{3}{*}{ Tardiness standard products } & $\begin{array}{l}\text { Between } \\
\text { groups }\end{array}$ & 3.00 & $160,952.00$ & $53,651.00$ & \multirow[t]{3}{*}{11.22} & \multirow[t]{3}{*}{0.00} \\
\hline & & $\begin{array}{l}\text { Within } \\
\text { grouns }\end{array}$ & 34000 & 1626.44800 & 4784.00 & & \\
\hline & & Total & 343.00 & $1,787,400.00$ & & & \\
\hline & \multirow[t]{3}{*}{ WIP standard products } & $\begin{array}{l}\text { Between } \\
\text { groups } \\
\text { Within }\end{array}$ & 3.00 & $5,849,856.00$ & $1,949,952.00$ & \multirow[t]{3}{*}{30.14} & \multirow[t]{3}{*}{0.00} \\
\hline & & groups & 8632.00 & $558,516,155.00$ & $64,703.00$ & & \\
\hline & & Total & 8635.00 & $564,366,011.00$ & & & \\
\hline & \multirow[t]{3}{*}{$\begin{array}{l}\text { Shop floor employees' } \\
\text { utilisation }\end{array}$} & $\begin{array}{l}\text { Between } \\
\text { groups }\end{array}$ & 3.00 & 0.08 & 0.03 & \multirow[t]{3}{*}{2.18} & \multirow[t]{3}{*}{0.09} \\
\hline & & groups & $17,268.00$ & 220.83 & 0.13 & & \\
\hline & & Total & $17,271.00$ & 220.91 & & & \\
\hline & \multirow[t]{3}{*}{ Developers' utilisation } & $\begin{array}{l}\text { Between } \\
\text { groups }\end{array}$ & 3.00 & 0.01 & 0.00 & \multirow[t]{3}{*}{1.04} & \multirow[t]{3}{*}{0.37} \\
\hline & & $\begin{array}{l}\text { Within } \\
\text { groups }\end{array}$ & 8732.00 & 32.32 & 0.00 & & \\
\hline & & Total & 8735.00 & 32.33 & & & \\
\hline \multirow[t]{18}{*}{$10 \% \mathrm{SP}$} & \multirow[t]{3}{*}{ Tardiness standard products } & $\begin{array}{l}\text { Between } \\
\text { groups }\end{array}$ & 3.00 & $138,096.00$ & $46,032.00$ & \multirow[t]{3}{*}{11.64} & \multirow[t]{3}{*}{0.00} \\
\hline & & $\begin{array}{l}\text { Within } \\
\text { groups }\end{array}$ & 340.00 & $1,344,134.00$ & 3953.00 & & \\
\hline & & Total & 343.00 & $1,482,230.00$ & & & \\
\hline & \multirow[t]{3}{*}{ Tardiness special projects } & $\begin{array}{l}\text { Between } \\
\text { groups }\end{array}$ & 3.00 & 838.00 & 279.40 & \multirow[t]{3}{*}{0.01} & \multirow[t]{3}{*}{1.00} \\
\hline & & groups & 22.00 & $652,623.00$ & $29,664.70$ & & \\
\hline & & Total & 25.00 & $653,462.00$ & & & \\
\hline & \multirow[t]{3}{*}{ WIP standard products } & $\begin{array}{l}\text { Between } \\
\text { groups } \\
\text { Within }\end{array}$ & 3.00 & $7,192,498.00$ & $2,397,499.00$ & \multirow[t]{3}{*}{50.97} & \multirow[t]{3}{*}{0.00} \\
\hline & & groups & 8632.00 & $406,064,934.00$ & $47,042.00$ & & \\
\hline & & Total & 8635.00 & $413,257,432.00$ & & & \\
\hline & \multirow[t]{3}{*}{ WIP special projects } & $\begin{array}{l}\text { Between } \\
\text { groups } \\
\text { Within }\end{array}$ & 3.00 & 37.77 & 12.59 & \multirow[t]{3}{*}{15.32} & \multirow[t]{3}{*}{0.00} \\
\hline & & groups & 8872.00 & 7292.67 & 0.82 & & \\
\hline & & Total & 8875.00 & 7330.44 & & & \\
\hline & \multirow[t]{3}{*}{$\begin{array}{l}\text { Shop floor employees' } \\
\text { utilisation }\end{array}$} & $\begin{array}{l}\text { Between } \\
\text { groups } \\
\text { Within }\end{array}$ & 3.00 & 0.08 & 0.03 & 10.90 & 0.00 \\
\hline & & groups & $17,268.00$ & 40.52 & 0.00 & & \\
\hline & & Total & $17,271.00$ & 40.59 & & & \\
\hline & Developers' utilisation & $\begin{array}{l}\text { Between } \\
\text { groups } \\
\text { Within }\end{array}$ & 3.00 & 131.90 & 43.96 & 11.79 & 0.00 \\
\hline & & groups & 8732.00 & $32,563.10$ & 3.73 & & \\
\hline & & Total & 8735.00 & $32,695.00$ & & & \\
\hline $20 \% \mathrm{SP}$ & Tardiness standard products & $\begin{array}{l}\text { Between } \\
\text { groups } \\
\text { Within }\end{array}$ & 3.00 & $174,306.00$ & $58,102.00$ & 12.38 & 0.00 \\
\hline & & groups & 340.00 & $1,595,901.00$ & 4694.00 & & \\
\hline & & Total & 343.00 & $1,770,207.00$ & & & \\
\hline
\end{tabular}


Table 1. (Continued).

\begin{tabular}{|c|c|c|c|c|c|c|c|c|c|c|c|}
\hline & & & & \multicolumn{2}{|c|}{$\begin{array}{l}\text { Degrees of } \\
\text { freedom }\end{array}$} & \multicolumn{2}{|c|}{ Sum of squares } & \multicolumn{2}{|c|}{ Mean square } & $F$-value & $P$-value \\
\hline & Tardiness special projects & $\begin{array}{l}\text { Be } \\
\text { gr } \\
\text { W } \\
\text { gr } \\
\text { To }\end{array}$ & $\begin{array}{l}\text { een } \\
\text { ps } \\
\text { in } \\
\text { ps }\end{array}$ & \multicolumn{2}{|l|}{3.00} & \multicolumn{2}{|c|}{$117,504.00$} & \multicolumn{2}{|c|}{$39,168.00$} & 0.32 & 0.81 \\
\hline & WIP standard products & \multicolumn{2}{|c|}{$\begin{array}{l}\text { Between } \\
\text { groups } \\
\text { Within } \\
\text { groups } \\
\text { Total }\end{array}$} & \multicolumn{2}{|l|}{3.00} & \multicolumn{2}{|c|}{$8,628,932.00$} & \multicolumn{2}{|c|}{$2,876,311.00$} & 88.63 & 0.00 \\
\hline & WIP special projects & \multicolumn{2}{|c|}{$\begin{array}{l}\text { Between } \\
\text { groups } \\
\text { Within } \\
\text { groups } \\
\text { Total }\end{array}$} & \multicolumn{2}{|l|}{3.00} & \multicolumn{2}{|l|}{22.90} & \multicolumn{2}{|l|}{7.64} & 1.44 & 0.23 \\
\hline & $\begin{array}{l}\text { Shop floor employees' } \\
\text { utilisation }\end{array}$ & \multicolumn{2}{|c|}{$\begin{array}{l}\text { Between } \\
\text { groups } \\
\text { Within } \\
\text { groups } \\
\text { Total }\end{array}$} & \multicolumn{2}{|l|}{3.00} & \multicolumn{2}{|l|}{0.20} & \multicolumn{2}{|l|}{0.07} & 444.89 & 0.00 \\
\hline & Developers' utilisation & & $\begin{array}{l}\text { een } \\
\text { os } \\
\text { in } \\
\text { os }\end{array}$ & $\begin{array}{l}3.00 \\
8732.0 \\
8735.0\end{array}$ & & $\begin{array}{l}435.80 \\
75,118.40 \\
75,554.10\end{array}$ & & $\begin{array}{l}145.25 \\
8.60\end{array}$ & & $\begin{array}{r}16.25 \\
8.60\end{array}$ & 0.00 \\
\hline (b) Tukey-Kramer & s test & & & & & & & & & & \\
\hline & Tardines & standard & oducts & WIP s & andard & roducts & $\begin{array}{l}\text { WIP special } \\
\text { projects }\end{array}$ & $\begin{array}{l}\text { Shor } \\
\text { empl } \\
\text { utili }\end{array}$ & $\begin{array}{l}\text { loor } \\
\text { ees' } \\
\text { ion }\end{array}$ & $\begin{array}{r}\text { Devel } \\
\text { utilis }\end{array}$ & $\begin{array}{l}\text { opers' } \\
\text { ation }\end{array}$ \\
\hline Comparison & No SP & $10 \% \mathrm{SP}$ & $\begin{array}{l}20 \% \\
\text { SP }\end{array}$ & $\begin{array}{l}\text { No } \\
\text { SP }\end{array}$ & $\begin{array}{l}10 \% \\
\mathrm{SP}\end{array}$ & $\begin{array}{l}20 \% \\
\mathrm{SP}\end{array}$ & $\begin{array}{l}10 \% \\
\mathrm{SP}\end{array}$ & $\begin{array}{l}10 \% \\
\mathrm{SP}\end{array}$ & $\begin{array}{l}20 \% \\
\mathrm{SP}\end{array}$ & $\begin{array}{l}10 \% \\
\mathrm{SP}\end{array}$ & $\begin{array}{l}20 \% \\
\text { SP }\end{array}$ \\
\hline EDF - FIFO & SD & SD & SD & SD & SD & SD & SD & NSD & SD & SD & NSD \\
\hline EDF - SPTF & SD & SD & $\mathrm{SD}$ & SD & SD & $\mathrm{SD}$ & $\mathrm{SD}$ & SD & SD & NSD & NSD \\
\hline EDF - PB-EDF & NSD & NSD & NSD & NSD & NSD & NSD & NSD & SD & SD & NSD & SD \\
\hline FIFO - SPTF & NSD & NSD & NSD & $\mathrm{SD}$ & $\mathrm{SD}$ & $\mathrm{SD}$ & $\mathrm{SD}$ & SD & SD & SD & SD \\
\hline FIFO - PB-EDF & SD & SD & SD & SD & NSD & SD & NSD & SD & SD & SD & NSD \\
\hline SPTF - PB-EDF & SD & SD & SD & SD & SD & SD & SD & NSD & SD & NSD & SD \\
\hline
\end{tabular}

Notes: SD - significantly different; NSD - Not significantly different.

priority over the MTO products. For this, the problem of deciding the queue position of the ETO components was not applicable.

The WIP levels, measured as the number of components in production, for the standard products are presented in Figure 7(c). For the special projects, Figure 7(d) presents the results for the number of special projects in production. The ANOVA results in Table 1(a) show significant differences in the WIP levels for the different queuing policies, in the different demand patterns, except for the WIP of the special projects when $20 \%$ of orders are special projects. Differences in the WIP performance for higher percentage of special projects are negligible. The Tukey-Kramer's test results show the SPTF policy performing best for the WIP of the standard products, with the lowest WIP values. The achieved performance levels for the SPTF policy may be justified by the fact that under this policy, jobs tend to wait less time to be processed (Eilon and Cotterjll 1968). Considering this, queues at the work centres and the WIP levels, measured as the number of components in production, tend to be smaller.

The shop floor employees and developers' utilisation levels are presented, respectively, in Figures 7(e) and (f). Increases in the demand for special projects increase the average resources' utilisation. According to the results in 
Table 1(a), when there are no orders for special projects, neither the shop floor employees' utilisation, nor the project developers' utilisation vary significantly. This is in agreement with the literature (Eilon and Cotterjll 1968), where the resources idle time is independent of the queuing rules, but dependent on the workload. An increase in the demand for special projects induces significant differences in the human resources utilisation values, as the one-way ANOVA and Tukey-Kramer test show. Despite achieving significantly different results, it is not possible assessing a single best queuing policy for the human resources utilisation.

In Figure 7(f), the developers' utilisation exceeds the unit, meaning lack of resources to complete all the planned projects on schedule. To accomplish responsiveness, the utilisation should be below the unit (Ulrich and Eppinger 2012).

The late deliveries count considered the percentage of delivered orders against the total orders for the simulated period, and the percentage of orders delivered, delayed. Table 2 shows that in the simulation period, all demand for standard products is fulfilled in the different queuing policies, however, a higher percentage of the delayed deliveries is generally verified for the FIFO policy, and lower percentage for the PB-EDF policy. This agrees with the literature (Mizrak and Mirac Bayhan 2006), that identified the EDF policy as one of the best performing in terms of the proportion of tardy jobs achieved in a job shop environment. When $10 \%$ of the orders are for special projects, the EDF and FIFO policies fulfil a higher percentage of the total demand, and with less delayed orders. However, when $20 \%$ of the orders are for special projects, the SPTF policy achieves a higher percentage of fulfilled demand, followed by the FIFO and PB-EDF policies. The results obtained when there is demand for special projects are not as easily interpretable; however, a general decrease in the percentage of fulfilled demand for ETO products with the increase in the percentage of demand for special projects is verified. This also leads to a higher percentage of delayed deliveries at the level of the MTO orders. Despite this, there is no single policy that outperforms the remaining.

The results obtained show that it is impossible to identify a single queuing policy that performs best in all performance measures, under all circumstances. This agrees with the literature (Gupta and Sivakumar 2006). Also, results become less related to the existing literature, and more difficult to assess when the effects of the demand for special projects are considered. The performance of all queuing policies tends to degrade as demand for special projects increases. This may be due to an overall workload increase and the higher uncertainty induced in the system by the new product development process, e.g. as in the variable time of releasing the special projects for production at the shop floor, resulting from different availability of the developers or errors occurring during project development.

\section{Effect of process parameters on selected performance measures - DOE}

In the second stage of the model application and output assessment, the goal is determining the system parameters, related to the human resources and the project development influencing the performance of the system. To conduct the analysis we used full factorial design methodology of DOE (Antony 2014) to create the simulation input parameters and assess the model results. We considered the effects of four parameters, at two levels - low and high - as in Table 6 in Appendix 1. The selected parameters are human resources and project development related.

Figure 8 presents the main effects plots for the mean response values of the different performance measures, to the system parameters. On the one hand, higher curve magnitude represents a stronger impact; on the other hand, the sign of the main effect shows if the average performance value increases or decreases. The Pareto plots of the factor effects

Table 2. Percentage of fulfilled demand and percentage of delayed deliveries in the simulation period, for the different queuing policies and for the different demand patterns.

\begin{tabular}{|c|c|c|c|c|c|c|}
\hline & & \multirow[b]{2}{*}{ No SP } & \multicolumn{2}{|c|}{$10 \% \mathrm{SP}$} & \multicolumn{2}{|c|}{$20 \% \mathrm{SP}$} \\
\hline & & & Standard Products & Special Projects & Standard Products & Special Projects \\
\hline \multirow[t]{2}{*}{ EDF } & $\%$ fulfilled demand & 100.0 & 100.0 & 70.0 & 100.0 & 47.6 \\
\hline & $\%$ delayed deliveries & 19.8 & 19.8 & 71.4 & 41.9 & 90.0 \\
\hline \multirow[t]{2}{*}{ FIFO } & $\%$ fulfilled demand & 100.0 & 100.0 & 70.0 & 100.0 & 57.1 \\
\hline & $\%$ delayed deliveries & 43.0 & 50.0 & 71.4 & 69.8 & 91.7 \\
\hline \multirow[t]{2}{*}{ SPTF } & $\%$ fulfilled demand & 100.0 & 100.0 & 60.0 & 100.0 & 61.9 \\
\hline & $\%$ delayed deliveries & 30.2 & 40.7 & 83.3 & 51.2 & 92.3 \\
\hline \multirow[t]{2}{*}{ PB-EDF } & $\%$ fulfilled demand & 100.0 & 100.0 & 60.0 & 100.0 & 57.1 \\
\hline & $\%$ delayed deliveries & 10.5 & 14.0 & 83.3 & 29.1 & 83.3 \\
\hline
\end{tabular}


are presented in Figure 9. These plots allow detecting the parameter and interactions effects which are most relevant to the system under study. Any parameter extending beyond the vertical reference line is potentially relevant for the system.

From the analysis of the plots results in Figures 7(a) and (b), the number of shop floor employees and the probability of good quality standard products/projects have the stronger impact in the tardiness of the standard products and the percentage of delayed orders for the standard products, with the mean performance response increasing with a decrease in these parameters. The Pareto charts in Figure 9(a) and (b) show multiple parameters and interactions being relevant for the system. The mean tardiness of the special projects is predominantly affected by the percentage of total available time allocated to development, Figure 8(c), and the Pareto chart, Figure 9(c) shows that the time of project revision and the interaction between the percentage of total available time allocated to development and the time of project revision should not be neglected. The mean percentage of fulfilled demand for special projects, Figure 8(d) shows that the superimposed curves of the probability of good quality standard products/projects and time of project revision are the most influential, while the Pareto chart in Figure 9(d) shows that the interaction between the probability of good quality standard products/projects and the percentage of total available time allocated to development should neither be neglected. The percentage of delayed orders for special projects is predominantly influenced by the percentage of total available time allocated to development, Figure 8(e), with this parameter being the only extending beyond the reference line in the Pareto chart in Figure 9(e). The WIP levels for the standard products are mostly influenced by the probability of good quality standard products/projects and the number of shop floor employees, Figure 8(f), yet other parameters and their interactions should not be neglected, Figure $9(\mathrm{f})$. The WIP of the special projects, Figure $8(\mathrm{~g})$ is mostly influenced by the probability of good quality standard products/projects, but other factors' interactions should not be neglected,

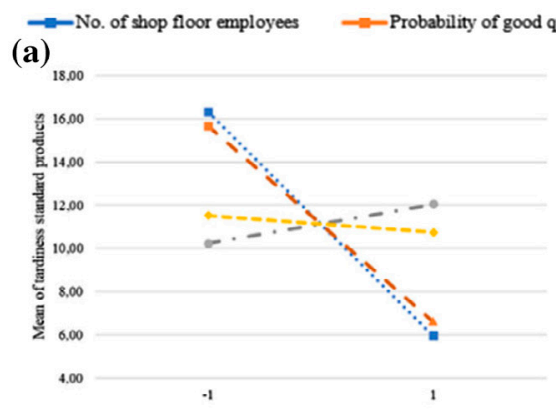

(d)
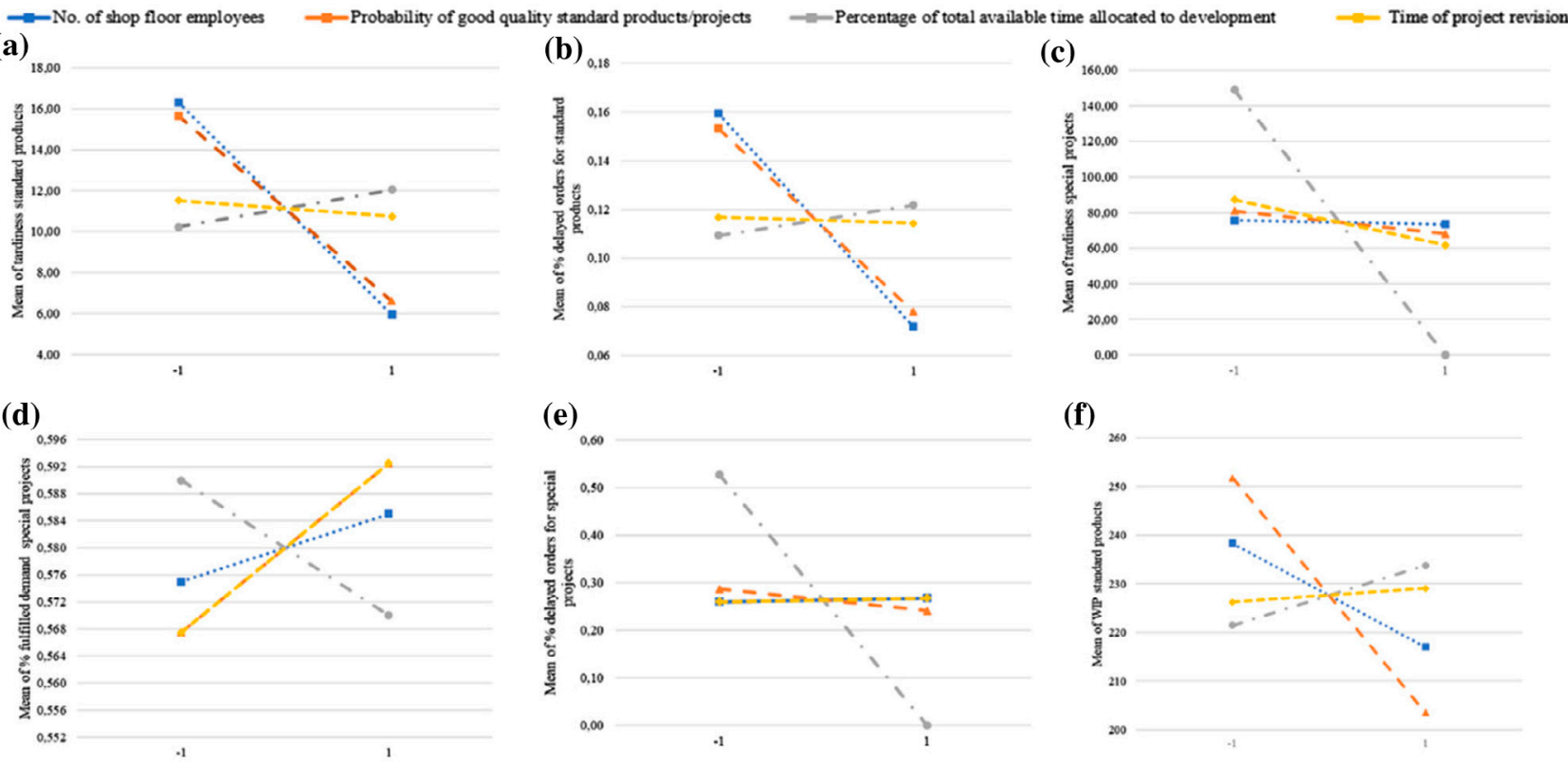

(e)

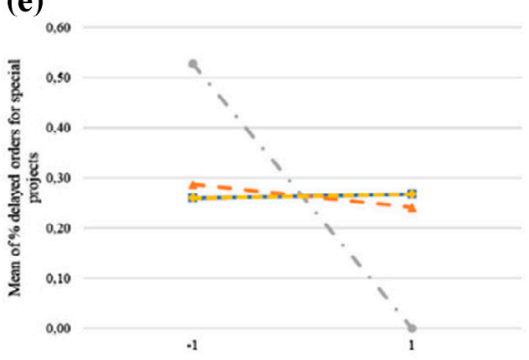

(f)

(g)

(h)
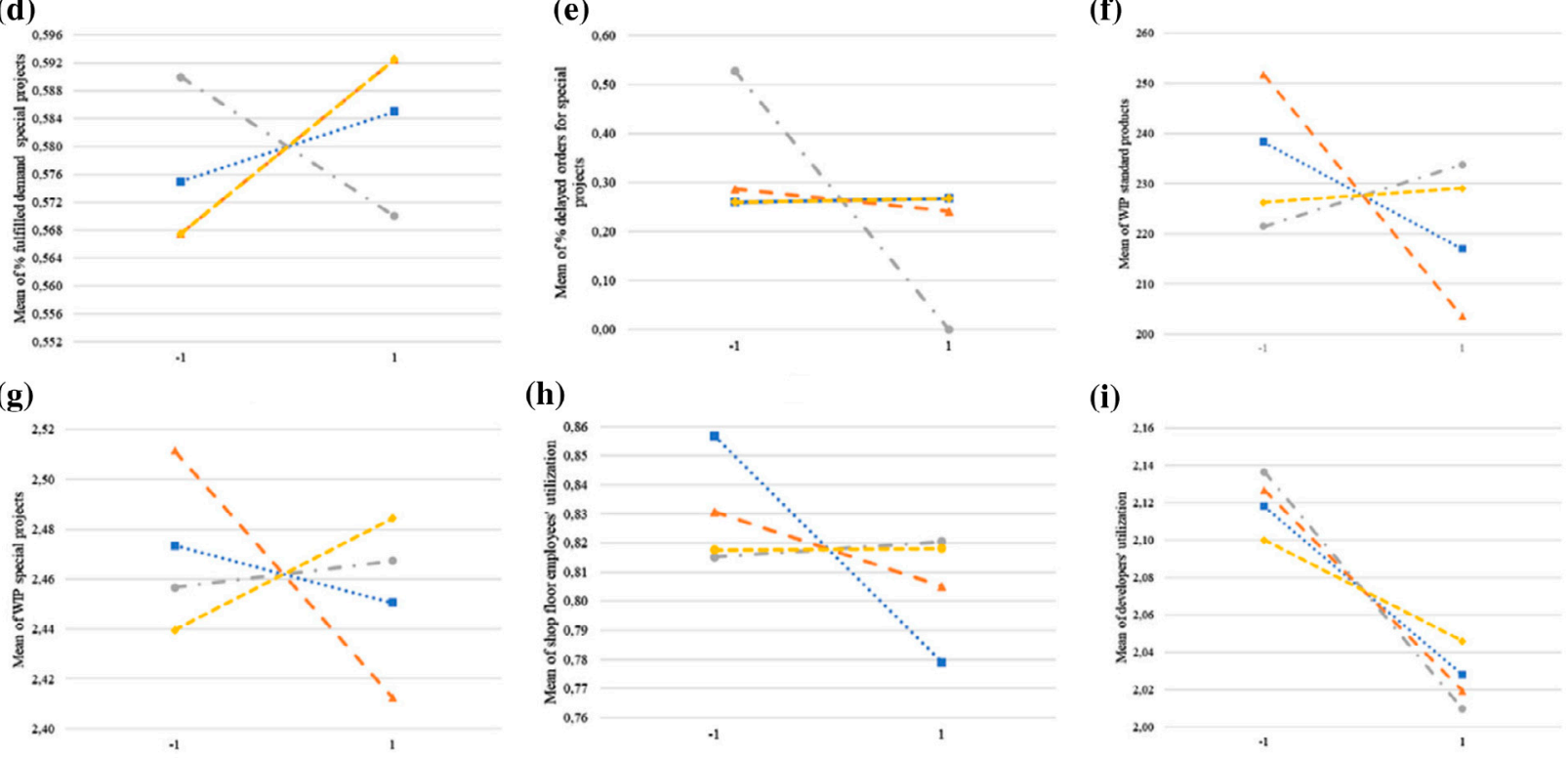

(i)

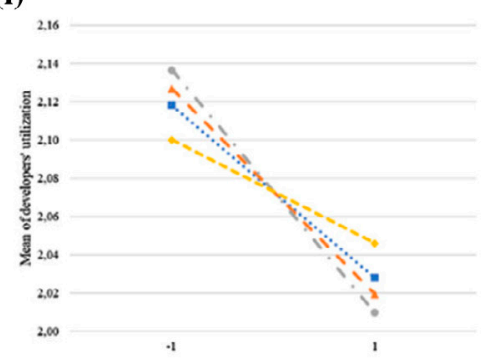

Figure 8. Main effects plots for the effects of the process parameters in the different performance measures. (a) Tardiness standard products, (b) \% delayed orders for standard products, (c) Tardiness special projects, (d) \% fulfilled demand for special projects, (e) \% delayed orders for special projects, (f) WIP standard products, (g) WIP special projects, (h) Shop floor employees' utilisation and (i) Developers' utilisation. 
A: Number of shop floor employees; B: Probability of good quality standard products/projects; C: Percentage of total available time allocated to

(a)

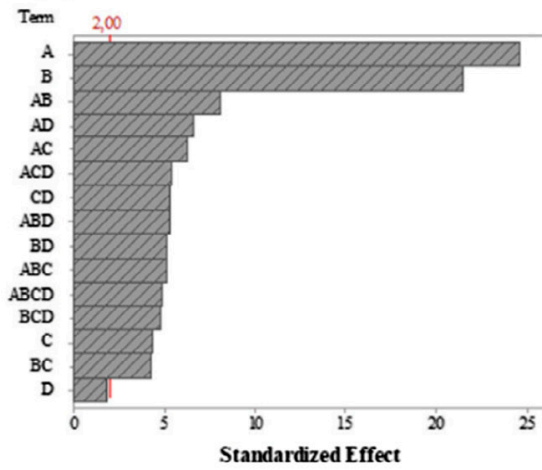

(d)

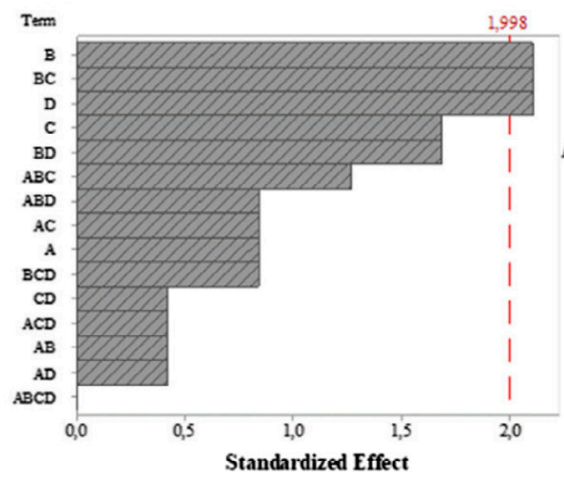

(g)

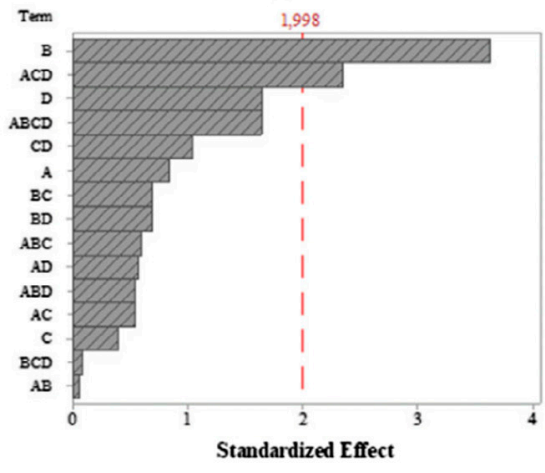

development; D: Time of project revision

(b)

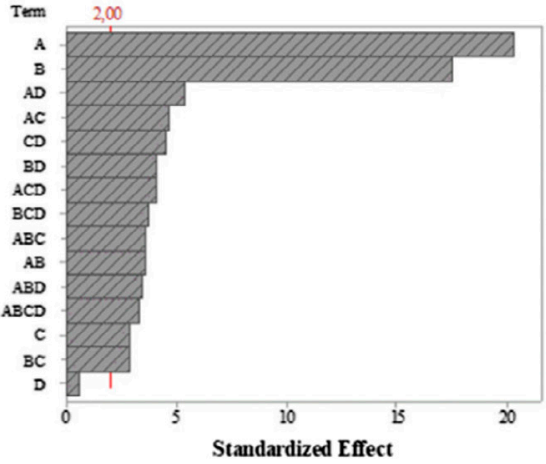

(e)

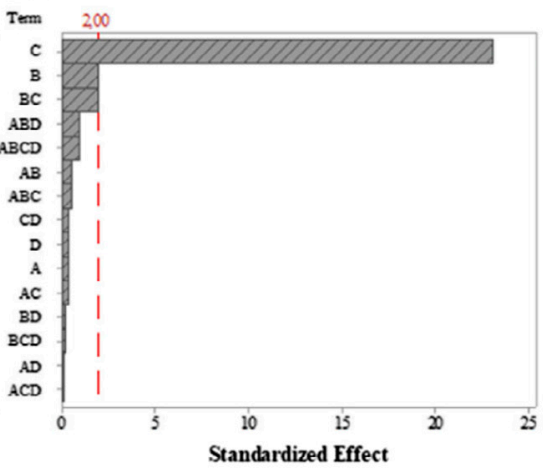

(h)

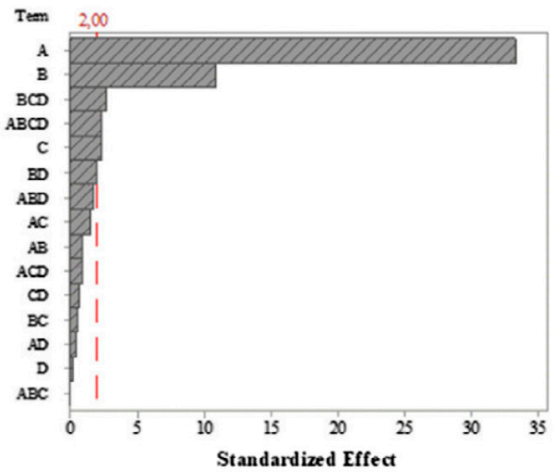

(c)

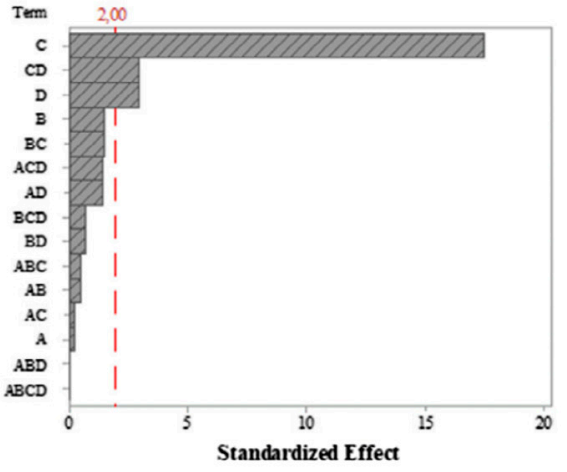

(f)

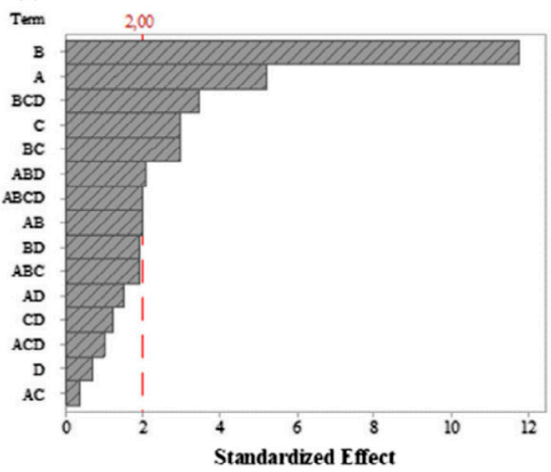

(i)

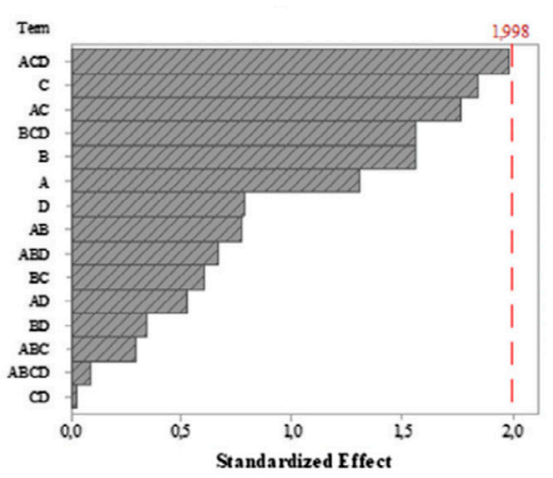

Figure 9. Pareto charts of the effects for the parameters and their interactions on the performance measures. (a) Tardiness standard products, (b) \% delayed orders for standard products, (c) Tardiness special projects, (d) \% fulfilled demand for special projects, (e) \% delayed orders for special projects, (f) WIP standard products, (g) WIP special projects, (h) Shop floor employees' utilisation and (i) Developers' utilisation.

Figure $9(\mathrm{~g})$. The shop floor employees' utilisation is mostly affected by the number of shop floor employees and the probability of good quality standard products/projects, as in Figure 8(h); however, other parameters and interactions should not be neglected, Figure 9(h). Finally, Figures 8(i) and 9(i) show that none of the considered parameters is particularly relevant for the developers' utilisation.

Overall, the performance measures related to special projects are mostly influenced by parameters directly related to the project development, as the percentage of total available time allocated to development and time of project revision. For standard products, the most relevant parameters are at those related to the shop floor, as the number of shop floor employees and the probability of good quality standard products/projects. From a practical perspective, this implies that environments combining MTO and ETO strategies should entail a close monitoring at the shop floor and product development levels, and not solely focusing in one of them, so better performance levels can be achieved. 


\section{Conclusions, improvements and future research directions}

In this work, we presented a hybrid SD-DES-ABS conceptual model framework for jointly analysing the development/customisation, production, resources allocation and management tasks in MTO/ETO environments. This framework is useful for predicting the performance of the system under different demand patterns and different operating policies, and assessing the system parameters that have most influence in performance.

The complexity of combined MTO/ETO environments calls for the use of simulation for performance assessment. The different nature and variety of problems that can arise in these environments demand using different approaches for analysing problems in different dimensions, but occurring in the same production environment. On the one hand, project development activities, capturing dynamic behaviour, with multiple project revisions and rework activities are better represented by a SD model. Production activities, with detailed routing of components in the shop floor and production policies implementation are better captured by a DES approach; and, human resources, particularly knowledge resources, are better simulated as agents, whose internal state affects the system performance. A hybrid simulation framework allows modelling complex and varied sub-systems interacting, without falling into cumbersome and improper use of methods, while taking advantage of the different methods' features.

Even though the simulation framework is valuable for performance assessment in combined MTO/ETO strategies, it only has been applied to a case study company. For the case study company, tardiness, WIP, human resources utilisation, and percentage of late deliveries have been assessed for different queuing policies in the shop floor. The results obtained when only demand for standard products is considered are aligned with the existing literature, however, when orders for special projects are considered results become more uncertain and difficult to assess. Obtained performance measures tend to degrade with the increase in demand for special projects. Several reasons may lead to this performance deterioration, as the variable time of releasing the special projects for production at the shop floor, resulting from different availability of the developers or errors occurring during project development. Also, operational parameters at the shop floor are most relevant for performance measures related to the standard products, while for special projects, parameters related to project development are more relevant.

Generalisation of the use of the framework is not possible at this stage, as it only has been applied to one case study. The results obtained are specific for the selected industrial case company. However, in view of the great resemblance between the selected case company and the literature features of MTO/ETO, the results obtained are still pertinent and a link between the results obtained and the existing literature is established. Also, further improvements to the models could be considered for increased accuracy of the results and resemblance to real systems. Future work should include improving the model e.g. by considering the different stages of the product development process, instead of the aggregated view herein assumed, consider the shop floor employees as agents, instead of entities, include a cost assessment model; and analysing the effect of more system parameters in performance and other operating policies.

\section{Disclosure statement}

No potential conflict of interest was reported by the authors.

\section{Funding}

This work was financially supported by the Fundação para a Ciência e Tecnologia (FCT) [grant number PD/BD/105988/2014]. This work is part of the Project 'TEC4Growth - Pervasive Intelligence, Enhancers and Proofs of Concept with Industrial Impact/NORTE01-0145-FEDER-000020' is financed by the North Portugal Regional Operational Programme (NORTE 2020), under the PORTUGAL 2020 Partnership Agreement, and through the European Regional Development Fund (ERDF).

\section{References}

Aburawi, Izidean, and Khalid Hafeez. 2009. "Managing Dynamics of Human Resource and Knowledge Management in Organizations through System Dynamics Modelling." International Journal of Sciences and Techniques of Automatic Control \& Computer Engineering 3 (2): 1108-1125.

Adrodegari, Federico, Andrea Bacchetti, Roberto Pinto, Fabiana Pirola, and Massimo Zanardini. 2015. "Engineer-to-Order (ETO) Production Planning and Control: An Empirical Framework for Machinery-Building Companies." Production Planning \& Control 26 (11): 910-932. doi:10.1080/09537287.2014.1001808.

Akinc, Umit, and Jack R. Meredith. 2015. "Make-to-Forecast: Customization with Fast Delivery." International Journal of Operations \& Production Management 35 (5): 728-750. doi:10.1108/IJOPM-12-2012-0567.

Alfieri, Arianna, Tullio Tolio, and Marcello Urgo. 2012. "A Two-stage Stochastic Programming Project Scheduling Approach to Production Planning." The International Journal of Advanced Manufacturing Technology 62 (1-4): 279-290. doi:10.1007/s00170011-3794-4. 
Antony, Jiju. 2014. Design of Experiments for Engineers and Scientists. 2nd ed. Oxford: Elsevier.

Balaji, J., and R.B. James. 2005. "Project Dynamics with Applications to Change Management and Earned Value Tracking." System Dynamics Society International Conference 2005, Boston, MA.

Barbosa, Cátia, and Américo Azevedo. 2015. "Evaluation of Improvement Actions Impact on Manufacturing Operational Performance." Paper presented at the 2015 IEEE International Conference on Industrial Engineering and Engineering Management (IEEM), December 6-9.

Barbosa, Cátia, and Américo Azevedo. 2017. "Hybrid Simulation for Complex Manufacturing Value-chain Environments." 27th International Conference on Flexible Automation and Intelligent Manufacturing, FAIM2017, Modena, Italy.

Beemsterboer, Bart, Martin Land, Ruud Teunter, and Jos Bokhorst. 2017. "Integrating Make-to-Order and Make-to-Stock in Job Shop Control." International Journal of Production Economics 185: 1-10. doi:10.1016/j.ijpe.2016.12.015.

Borshchev, Andrei, and Alexei Filippov. 2004. "From System Dynamics and Discrete Event to Practical Agent Based Modeling: Reasons, Techniques, Tools." 22nd International Conference of the System Dynamics Society, Oxford, England.

Chen, Chee-Cheng. 2008. "An Objective-oriented and Product-Line-based Manufacturing Performance Measurement." International Journal of Production Economics 112 (1): 380-390. doi:10.1016/j.ijpe.2007.03.016.

van Donk, Dirk Pieter, and Ron van Doorne. 2016. "The Impact of the Customer Order Decoupling Point on Type and Level of Supply Chain Integration.” International Journal of Production Research 54 (9):2572-2584. doi: 10.1080/00207543.2015.1101176.

Eilon, S., and D. J. Cotterj1l. 1968. "A Modified SI Rule in Job Shop Scheduling." International Journal of Production Research 7 (2): 135-145. doi:10.1080/00207546808929803.

Engwall, Mats, and Anna Jerbrant. 2003. "The Resource Allocation Syndrome: The Prime Challenge of Multi-project Management?" International Journal of Project Management 21 (6): 403-409. doi:10.1016/S0263-7863(02)00113-8.

Grabenstetter, Douglas H., and John M. Usher. 2014. "Developing Due Dates in an Engineer-to-Order Engineering Environment." International Journal of Production Research 52 (21): 6349-6361. doi:10.1080/00207543.2014.940072.

Grabenstetter, Douglas H., and John M. Usher. 2015. "Sequencing Jobs in an Engineer-to-Order Engineering Environment." Production \& Manufacturing Research 3 (1): 201-217. doi:10.1080/21693277.2015.1035461.

Gupta, Amit Kumar, and Appa Iyer Sivakumar. 2006. "Job Shop Scheduling Techniques in Semiconductor Manufacturing." The International Journal of Advanced Manufacturing Technology 27 (11-12): 1163-1169. doi:10.1007/s00170-004-2296-z.

Hao, Qi, and Weiming Shen. 2008. "Implementing a Hybrid Simulation Model for a Kanban-based Material Handling System." Robotics and Computer-Integrated Manufacturing 24 (5): 635-646. doi:10.1016/j.rcim.2007.09.012.

Hendry, Linda C. 2010. "Product Customisation: An Empirical Study of Competitive Advantage and Repeat Business." International Journal of Production Research 48 (13): 3845-3865. doi:10.1080/00207540902946579.

Hicks, C., and P. M. Braiden. 2000. "Computer-aided Production Management Issues in the Engineer-to-Order Production of Complex Capital Goods Explored Using a Simulation Approach.” International Journal of Production Research 38 (18): 47834810. doi:10.1080/00207540010001019.

Horng, Horng-Chyi. 2013. "Optimal Safety Stock Policy for a Hybrid Manufacturing System: A Simulation Study." In Advances in Sustainable and Competitive Manufacturing Systems: 23rd International Conference on Flexible Automation \& Intelligent Manufacturing, edited by Américo Azevedo, 295-306. Heidelberg: Springer.

Huot, Jean-Claude, and Y. Sylvestre. 1985. "An Application of System Dynamics to the Construction Management of Major Building." Systems Dynamics 85: 381-409.

Lättilä, Lauri, Per Hilletofth, and Bishan Lin. 2010. "Hybrid Simulation Models - When, Why, How?” Expert Systems with Applications 37 (12): 7969-7975. doi:10.1016/j.eswa.2010.04.039.

Lianjun, An, Jeng Jun-Jang, M. Lee Young, and Ren Changrui. 2007. "Effective Workforce Lifecycle Management via System Dynamics Modeling and Simulation.” Paper presented at the 2007 Winter Simulation Conference, December 9-12.

Lu, H. L., George Q. Huang, and H. D. Yang. 2011. "Integrating Order Review/Release and Dispatching Rules for Assembly Job Shop Scheduling Using a Simulation Approach.” International Journal of Production Research 49 (3): 647-669. doi:10.1080/ 00207540903524490.

Lyneis, James M., and David N. Ford. 2007. "System Dynamics Applied to Project Management: A Survey, Assessment, and Directions for Future Research.” System Dynamics Review 23 (2-3): 157-189.

Marzouk, Ahmed M., Hoda A. ElMaraghy, and Waguih H. ElMaraghy. 2016. "Effect of Changing Operating Policies on Energy Use Consumption.” Procedia CIRP 41: 301-306. doi:10.1016/j.procir.2015.10.002.

Mizrak, Pinar, and G. Mirac Bayhan. 2006. "Comparative Study if Dispatching Rules in a Real-Life Job Shop Environment." Applied Artificial Intelligence 20 (7): 585-607. doi:10.1080/08839510600779738.

Morgan, Jennifer Sian, Susan Howick, and Valerie Belton. 2016. "A Toolkit of Designs for Mixing Discrete Event Simulation and System Dynamics.” European Journal of Operational Research 257 (3): 907-918. doi:10.1016/j.ejor.2016.08.016.

Neely, Andy, Mike Gregory, and Ken Platts. 1995. "Performance Measurement System Design: A Literature Review and Research Agenda." International Journal of Operations \& Production Management 15 (4): 80-116. doi:10.1108/01443579510083622.

Nudurupati, S. S., U. S. Bititci, V. Kumar, and F. T. S. Chan. 2011. "State of the Art Literature Review on Performance Measurement." Computers \& Industrial Engineering 60 (2): 279-290. doi:10.1016/j.cie.2010.11.010.

Ostertagová, Eva, and Oskar Ostertag. 2013. "Methodology and Application of One-way ANOVA." American Journal of Mechanical Engineering 1 (7): 256-261. 
Rabelo, L., M. Helal, A. Jones, and H. S. Min. 2005. "Enterprise Simulation: A Hybrid System Approach.” International Journal of Computer Integrated Manufacturing 18 (6): 498-508. doi:10.1080/09511920400030138.

Rafiei, H., and M. Rabbani. 2011. "Order Partitioning and Order Penetration Point Location in Hybrid Make-to-Stock/Make-to-Order Production Contexts.” Computers \& Industrial Engineering 61 (3): 550-560. doi:10.1016/j.cie.2011.04.010.

Rafiei, Hamed, Masoud Rabbani, and Maryam Alimardani. 2013. "Novel Bi-level Hierarchical Production Planning in Hybrid MTS/ MTO Production Contexts." International Journal of Production Research 51 (5): 1331-1346. doi:10.1080/ 00207543.2012.661089.

Reddi, Krishna R., and Young B. Moon. 2013. "Modelling Engineering Change Management in a New Product Development Supply Chain." International Journal of Production Research 51 (17): 5271-5291. doi:10.1080/00207543.2013.807954.

Robinson, Stewart. 2004. Simulation: The Practice of Model Development and Use. Chichester: Wiley.

Robinson, S. 2008. "Conceptual Modelling for Simulation Part I: Definition and Requirements." Journal of the Operational Research Society 59: 278-290.

Rocha, Filipa, Emanuel Silva, Ângela Lopes, Luis Dias, Guilherme Pereira, Nuno O. Fernandes, and S. Carmo-Silva. 2015. "Materials Flow Control in Hybrid Make-to-Stock/Make-to-Order Manufacturing." In Computational Logistics: 6th International Conference, ICCL 2015, Delft, the Netherlands, September 23-25, 2015, Proceedings, edited by Francesco Corman, Stefan Voß and Rudy R. Negenborn, 559-568. Cham: Springer International Publishing.

Rodrigues, Alexandre. 1994. "The Role of System Dynamics in Project Management: A Comparative Analysis with Traditional Models." In International System Dynamics Conference Proceedings, Lincoln, MA.

Rodrigues, Alexandre, and John Bowers. 1996. "System Dynamics in Project Management: A Comparative Analysis with Traditional Methods." System Dynamics Review 12 (2): 121-139.

Rodrigues, Lewlyn L. R., N. Dharmaraj, and B. R. Shrinivasa Rao. 2006. "System Dynamics Approach for Change Management in New Product Development." Management Research News 29 (8): 512-523. doi:10.1108/01409170610692824.

Rudberg, Martin, and Joakim Wikner. 2004. "Mass Customization in Terms of the Customer Order Decoupling Point." Production Planning \& Control 15 (4): 445-458. doi:10.1080/0953728042000238764.

Rus, Ioana, James Collofello, and Peter Lakey. 1999. "Software Process Simulation for Reliability Management." Journal of Systems and Software 46 (2-3): 173-182. doi:10.1016/S0164-1212(99)00010-2.

Sargent, Robert G. 2011. "Verification and Validation of Simulation Models." In Proceedings of the 2011 Winter Simulation Conference (WSC), edited by S. Jain, R.R. Creasey, J. Himmelspach, K.P. White and M. Fu, 183-198.

Sterman, John D. 1992. "System Dynamics Modeling for Project Management." Unpublished manuscript, Cambridge, MA, 246.

Stevenson, M., L. C. Hendry, and B. G. Kingsman. 2005. "A Review of Production Planning and Control: The Applicability of Key Concepts to the Make-to-Order Industry." International Journal of Production Research 43 (5): 869-898. doi:10.1080/ 0020754042000298520 .

Swinerd, Chris, and Ken R. McNaught. 2012. "Design Classes for Hybrid Simulations Involving Agent-based and System Dynamics Models." Simulation Modelling Practice and Theory 25: 118-133. doi:10.1016/j.simpat.2011.09.002.

Ulrich, Karl T., and Steven D. Eppinger. 2012. Product Design and Development. 5th ed. McGraw-Hill.

Umeda, S., and F. Zhang. 2008. "Hybrid Modeling Approach for Supply-chain Simulation." In Lean Business Systems and Beyond, edited by Tomasz Koch, 453-460. Boston, MA: Springer US.

Venkateswaran, J., and Y. J. Son. 2005. "Hybrid System Dynamic - Discrete Event Simulation-based Architecture for Hierarchical Production Planning." International Journal of Production Research 43 (20): 4397-4429. doi:10.1080/00207540500142472.

Wang, F. Y., L. Xu, R. Lim, E. W. Lee, and M. and Zarzycki. 2011. "Simulation-based Operational Decision Analysis at Decoupling Point in MTS-MTO System.” Paper presented at the 2011 IEEE International Conference on Industrial Engineering and Engineering Management, December 6-9.

Wang, F., R. Piplani, L. X. X. Xia, and A. S. Bhullar. 2012. "MTS Lead Time Uncertainty Study in Periodic Review MTS-MTO System." Paper presented at the 2012 IEEE International Conference on Industrial Engineering and Engineering Management, December 10-13.

Wang, H., Y. Zheng, and M. Zhao. 2013. “A Framework for Integrating Discrete Event Simulation with Agent-based Modeling." Paper presented at the Proceedings of 2013 6th International Conference on Information Management, Innovation Management and Industrial Engineering, ICIII 2013, 176-180. doi:10.1109/ICIII.2013.6703542.

Wang, Bochao, Séverin Brême, and Young B. Moon. 2014. "Hybrid Modeling and Simulation for Complementing Lifecycle Assessment." Computers \& Industrial Engineering 69: 77-88. doi:10.1016/j.cie.2013.12.016.

Willner, Olga, Daryl Powell, Aldo Duchi, and Paul Schönsleben. 2014. "Globally Distributed Engineering Processes: Making the Distinction Between Engineer-to-Order and Make-to-Order.” Procedia CIRP 17 (Supplement C): 663-668. doi:10.1016/j.procir.2014.02.054.

Wu, Muh-Cherng, Jr-Hsiung Jiang, and Wen-Jen Chang. 2008. "Scheduling a Hybrid MTO/MTS Semiconductor Fab with Machinededication Features.” International Journal of Production Economics 112 (1): 416-426. doi:10.1016/j.ijpe.2007.04.008.

Yang, Li-Ren. 2013. "Key Practices, Manufacturing Capability and Attainment of Manufacturing Goals: The Perspective of Project/Engineer-to-Order Manufacturing." International Journal of Project Management 31: 109-125. doi:10.1016/j.ijproman.2012.03.005.

Zschorn, Lars, Steve Müller, and Dmitry Ivanov. 2016. "Cost Analysis of Capacity Flexibility in a Hybrid Multiple-Line Production System at Siemens AG.” IFAC-PapersOnLine 49 (12): 1278-1282. doi:10.1016/j.ifacol.2016.07.699. 


\section{Appendices}

Table 3. Processing time average and standard deviation (Std.), in minutes, for each component in the different product families and WC routing order for each product in the different WCs.

\begin{tabular}{|c|c|c|c|c|c|c|}
\hline & & \multicolumn{5}{|c|}{ Product family } \\
\hline & & A B & B C D & E & $\mathrm{F}$ & G \\
\hline WC1 Processing & Average & 5 & 275 & Compound product: & Compound product: & Compound product: \\
\hline Time & Std. & 11 & $\begin{array}{lll}1 & 1 & 1\end{array}$ & $1 \mathrm{~A}+2 \mathrm{~B}$ & $2 \mathrm{~A}+3 \mathrm{D}$ & $1 \mathrm{~A}+2 \mathrm{D}+1 \mathrm{C}$ \\
\hline Order & & & $\begin{array}{lll}1 & 1 & 1\end{array}$ & & & \\
\hline WC2 Processing & Average & 2012 & $230-$ & & & \\
\hline Time & Std. & 32 & $23-$ & & & \\
\hline Order & & 23 & $33-$ & & & \\
\hline WC3 Processing & Average & 45 & 523 & & & \\
\hline Time & Std. & 12 & $\begin{array}{lll}2 & 1 & 1\end{array}$ & & & \\
\hline Order & & 4 & 442 & & & \\
\hline WC4 Processing & Average & 3 & $56-$ & & & \\
\hline Time & Std. & 1 & $21-$ & & & \\
\hline Order & & 32 & $22-$ & & & \\
\hline WC5 Processing & Average & 1013 & 394 & & & \\
\hline Time & Std. & 34 & $4 \quad 21$ & & & \\
\hline Order & & 55 & 555 & & & \\
\hline WC6 Processing & Average & 8 & 487 & & & \\
\hline Time & Std. & 2 & 122 & & & \\
\hline Order & & 66 & 666 & & & \\
\hline
\end{tabular}

Table 4. Average and standard deviation (Std.) processing times, in days, for the special projects in each WC.

\begin{tabular}{lcccccc}
\hline & WC1 & WC2 & WC3 & WC4 & WC5 & WC6 \\
\hline Average & 6 & 9 & 8 & 5 & 7 & 6 \\
Std. & 2 & 4 & 2 & 1 & 2 & 2 \\
\hline
\end{tabular}

Table 5. Process parameters data, where M1 represents machine type 1, M2 represents machine type 2, M3 represents machine type 3, M4 represents machine type 4, M5 represents machine type 5, M6 represents machine type 6, M3.1 represents machine type 3 used in special projects, and M4.1 represents machine type 4 used in special projects.

\section{Resources data}

Initial number of new project developers

Initial number of experienced project developers

Productivity of new project developers

Productivity of experienced project developers

Rate of developers becoming experienced

Quit rate new developers

Quit rate experienced developers

Number of shop floor employees

Number of machines

Machine time to failure (months)

Machine time to repair (minutes)

Machine time to next failure (weeks)

Probability of good quality standard products

Probability of good quality special projects

Product development data

Scope of project revision

Time of project revision

Rejection normal

Percentage of total available time allocated to development

Initial level of available materials in each project

Workforce management data

Desired utilisation of project developers

Maximum number of project developers

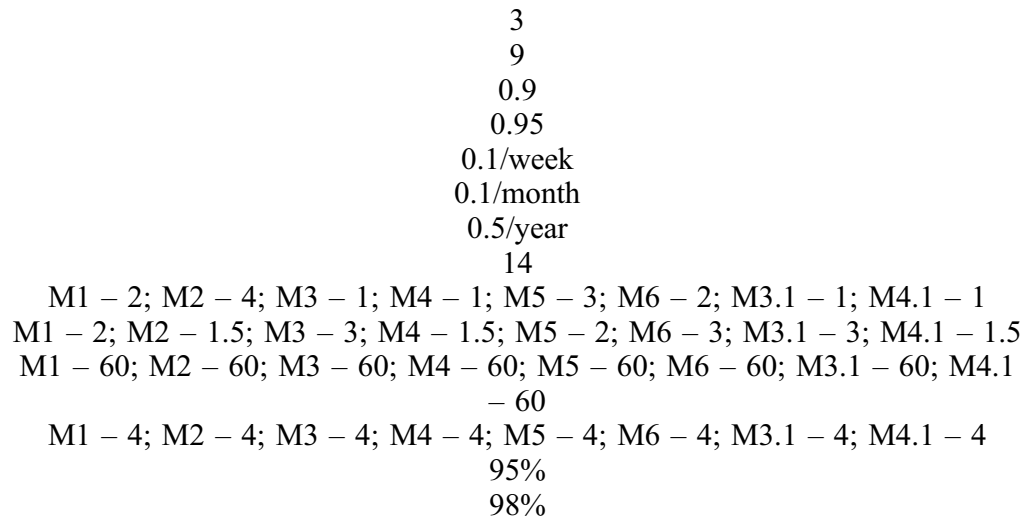

$10 \%$ of initial project workload

First revision $-1 / 2$ of the initial project schedule; Other revisions - every $250 \mathrm{~h}$ of work.

$5 \%$

$25 \%$

$1.5 *$ initial project workload 
Table 6. Low and high levels of the parameters used in the study of the impact in performance measures.

\begin{tabular}{|c|c|c|}
\hline Parameter & Low $(-1)$ & High (1) \\
\hline Number of shop floor employees & 14 & 16 \\
\hline $\begin{array}{l}\text { Probability of good quality } \\
\text { standard products/projects }\end{array}$ & $90 / 95 \%$ & $95 / 100 \%$ \\
\hline $\begin{array}{l}\text { Percentage of total available time } \\
\text { allocated to development }\end{array}$ & $25 \%$ & $30 \%$ \\
\hline Time of project revision & $\begin{array}{l}\text { First revision }-1 / 2 \text { of the initial project schedule; } \\
\text { Other revisions - every } 350 \mathrm{~h} \text { of work. }\end{array}$ & $\begin{array}{l}\text { First revision }-1 / 2 \text { of the initial project schedule; } \\
\text { Other revisions - every } 250 \mathrm{~h} \text { of work. }\end{array}$ \\
\hline
\end{tabular}

